\title{
A Case Study of a Transported Bromine Explosion Event in the Canadian High Arctic
}

X. Zhao ${ }^{1}$, K. Strong ${ }^{1}$, C. Adams ${ }^{1, *}$, R. Schofield ${ }^{2,3}$, X. Yang ${ }^{4}$, A. Richter ${ }^{5}$, U. Friess $^{6}$, A.-M. Blechschmidt ${ }^{5}$, J.-H. Koo ${ }^{1}$

[1] \{Department of Physics, University of Toronto, Toronto, Ontario, Canada\}

[2]\{School of Earth Sciences, University of Melbourne, Parkville, Australia\}

[3] \{ARC Centre of Excellence for Climate System Science, University of New South Wales, Australia\}

[4]\{British Antarctic Survey, National Environment Research Council, Cambridge, UK\}

[5]\{Institute of Environmental Physics, University of Bremen, Bremen, Germany\}

[6] \{Institute of Environmental Physics, University of Heidelberg, Heidelberg, Germany\}

[*]\{now at: Alberta Environment, Edmonton, Alberta, Canada\}

Correspondence to: Xiaoyi Zhao (xizhao@atmosp.physics.utoronto.ca)

This article has been accepted for publication and undergone full peer review but has not been through the copyediting, typesetting, pagination and proofreading process which may lead to differences between this version and the Version of Record. Please cite this article as doi: 10.1002/2015JD023711 


\section{Abstract}

Ozone depletion events in the polar troposphere have been linked to extremely high concentrations of bromine, known as bromine explosion events (BEE). However the optimum meteorological conditions for the occurrence of these events remain uncertain. On 4-5 April 2011, a combination of both blowing snow and a stable shallow boundary layer was observed during a BEE at Eureka, Canada $\left(86.4^{\circ} \mathrm{W}, 80.1^{\circ} \mathrm{N}\right)$. Measurements made by a Multi-Axis Differential Optical Absorption Spectroscopy (MAX-DOAS) spectrometer were used to retrieve $\mathrm{BrO}$ profiles and partial columns. During this event, the near-surface $\mathrm{BrO}$ volume mixing ratio increased to $\sim 20 \mathrm{pptv}$, while ozone was depleted to $\sim 1 \mathrm{ppbv}$ from the surface to $700 \mathrm{~m}$. Back-trajectories and GOME-2 satellite tropospheric BrO columns confirmed that this event originated from a bromine explosion over the Beaufort Sea. From 30 to 31 March, meteorological data showed high wind speeds $(24 \mathrm{~m} / \mathrm{s})$ and elevated boundary layer heights $(\sim 800 \mathrm{~m})$ over the Beaufort Sea. Long-distance transportation $(\sim 1,800$ $\mathrm{km}$ over five days) to Eureka indicated strong recycling of $\mathrm{BrO}$ within the bromine plume. This event was generally captured by a global chemistry-climate model when a sea-salt bromine source from blowing snow was included. A model sensitivity study indicated that the surface $\mathrm{BrO}$ at Eureka was controlled by both local photochemistry and boundary layer dynamics. Comparison of the model results with both ground-based and satellite measurements confirmed that the BEE observed at Eureka was triggered by transport of enhanced $\mathrm{BrO}$ from the Beaufort Sea followed by local production/recycling under stable atmospheric shallow boundary layer conditions.

\section{Key Points:}

- A transported bromine explosion event was observed in the Canadian High Arctic

- Both blowing snow and a stable shallow boundary layer were observed during the event

- The bromine explosion event is simulated by a global chemistry-climate model

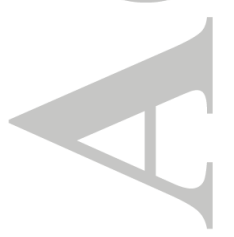




\section{Introduction}

Severe surface ozone depletion events (ODEs) were first observed in the Arctic troposphere [Bottenheim et al., 1986; Barrie et al., 1988]. These events have since been linked to extremely high concentrations of bromine as reviewed by Simpson et al. [2007b] and Abbatt et al. [2012]. The initial release of bromine radicals from ions

$$
\begin{aligned}
& \mathrm{HOBr}+\mathrm{Br}^{-}{ }_{(a q)}+\mathrm{H}^{+}{ }_{(a q)} \stackrel{m p}{\longrightarrow} \mathrm{Br}_{2}+\mathrm{H}_{2} \mathrm{O} \\
& \mathrm{Br}_{2} \stackrel{h v}{\longrightarrow} 2 \mathrm{Br} \\
& \mathrm{Br}+\mathrm{O}_{3} \rightarrow \mathrm{BrO}+\mathrm{O}_{2}
\end{aligned}
$$

(where $\mathrm{mp}$ indicates a multiphase reaction) can be followed by self-reaction $(\mathrm{BrO}+\mathrm{BrO})$, cross reaction $(\mathrm{BrO}+\mathrm{IO} / \mathrm{ClO})$, and catalytic cycles involving $\mathrm{HO}_{2}$ and $\mathrm{CO}$ [Simpson et al., 2007b]. However, these three reaction pathways (self-reaction, cross reaction, and the catalytic cycles) do not increase the abundance of the $\mathrm{BrO}_{\mathrm{x}}$ family $(\mathrm{Br}+\mathrm{BrO})$, and thus do not speed up the depletion of ozone. The widely accepted mechanism for the bromine explosion cycle proceeds via the reaction

$$
\mathrm{BrO}+\mathrm{HO}_{2} \rightarrow \mathrm{HOBr}+\mathrm{O}_{2}
$$

Combining reactions $\mathrm{R} 1-\mathrm{R} 4$ gives the net reaction

$\mathrm{Br}+\mathrm{Br}_{(a q)}^{-}+\mathrm{H}_{(a q)}^{+}+\mathrm{O}_{3}+\mathrm{HO}_{2} \stackrel{m p, h v}{\longrightarrow} 2 \mathrm{Br}+2 \mathrm{O}_{2}+\mathrm{H}_{2} \mathrm{O}$.

Followed by rapid ozone depletion in some conditions, this cycle could result in the conversion of particle-phase inactive bromide $(\mathrm{Br}-)$ to gas-phase reactive bromine $\left(\mathrm{BrO}_{\mathrm{x}}\right)$, thus further speeding up the cycle. This is the widely known bromine explosion reaction sequence [Fan and Jacob, 1992; McConnell et al., 1992; Wennberg, 1999]. In addition, the reaction of gas-phase reactive bromine $\left(\mathrm{BrO}_{\mathrm{x}}\right)$ with gas-phase elemental mercury can lead to toxic mercury deposition in polar ecosystems [Schroeder et al., 1998].

Although bromine explosion events have been extensively studied over the past two decades, many questions remain. Studies of the surface on which reaction R1 proceeds have suggested that this surface may be sea salt deposited on the snowpack and ice [McConnell et al., 1992; Simpson et al., 2007a; Dibb et al., 2010; Pratt et al., 2013], acidified background sea-salt aerosol [Vogt et al., 1996], brines concentrated on frost flowers that form on young sea ice 
[Rankin et al., 2002; Kaleschke et al., 2004], and bromine in blowing snow [Yang et al., 2008; Jones et al., 2009]. Brines concentrated on frost flowers are no longer considered as a pathway for bromine activation primarily due to its high $\mathrm{pH}$ which is not favorable for $\mathrm{Br}_{2}$ formation [Abbatt et al., 2012; Pratt et al., 2013; Wren et al., 2013]. The optimum meteorological conditions for the occurrence of bromine explosion events also remain uncertain. A stable shallow boundary layer [Wagner et al., 2001; Frieß et al., 2004; Lehrer et al., 2004] and blizzard conditions [Yang et al., 2008; Jones et al., 2009; Frieß et al., 2011] have both been proposed. These different meteorological conditions can lead to different transportation patterns for the low-ozone airmass, thereby changing the oxidative capacity of the Arctic troposphere.

$\mathrm{BrO}$ is one of the dominant species indicative of radical bromine chemistry, and has been measured by various satellite and ground-based instruments. One method for measuring tropospheric BrO is Multi-Axis Differential Optical Absorption Spectroscopy (MAXDOAS), which has detection limits of 1-2 parts per trillion by volume (pptv), varying with visibility [Hönninger et al., 2004; Platt and Stutz, 2008]. For comparison, the BrO detection limits for in-situ chemical ionization mass spectroscopy [Neuman et al., 2010; Liao et al., 2012; Peterson et al., 2015] and long-path DOAS [Frieß et al., 2011; Liao et al., 2011] are 0.3-3 and 0.7-2 pptv respectively. Ground-based instruments can provide good temporal coverage and some vertical profile resolution [Frieß et al., 2011; Peterson et al., 2015], while nadir-viewing satellite instruments can be used to study bromine explosion events on the global scale [e.g., Richter et al., 1998]. However, nadir-viewing UV-visible spectrometers have limited vertical resolution, making it difficult to separate $\mathrm{BrO}$ signals from the boundary layer, the free troposphere, and the stratosphere. Salawitch et al. [2010] showed that some of the locations of satellite BrO "hotspots" during Arctic spring can be associated with observations of elevated total column ozone and low tropopause height, suggesting a stratospheric origin for these regions of enhanced "tropospheric" bromine. Choi et al. [2012] also showed that the tropopause height is important, and that properly accounting for the stratospheric signal is essential for accurate determination of satellite-derived tropospheric $\mathrm{BrO}$, but for most clear-sky conditions, satellite measurements were in reasonable agreement with aircraft in-situ observations in the troposphere. Theys et al. [2011] and Koo et al. [2012] demonstrated that tropospheric $\mathrm{BrO}$ columns reflect the near-surface ozone depletion pattern. The partitioning of satellite-based BrO vertical column densities (VCDs) between the troposphere and stratosphere can be undertaken using the methods of Theys et al. [2011] and 
Sihler et al. [2012].

In this work, we examine a bromine explosion event associated with both blowing snow and a stable shallow boundary layer above Eureka, Canada in April 2011. From 3 to 5 April 2011, 0-4 km BrO partial columns measured in the Canadian High Arctic at the Polar Environment Atmospheric Research Laboratory (PEARL, Fogal et al. [2013]) using ground-based MAXDOAS were enhanced by a factor of three compared to previous days. We investigate the bromine explosion event and find that it was initiated during blowing snow conditions over the Beaufort Sea and transported to Eureka. In addition to low visibility conditions observed over Eureka for the first two days after the bromine plume arrived, we also observed local recycling of $\mathrm{BrO}$ over Eureka in calm and clear weather conditions on the third day of the event. To determine the source of this bromine explosion event and the driving meteorological conditions, we present an investigation of ground-based, satellite, and modeled $\mathrm{BrO}$ and ozone datasets. A nudged version of the UM-UKCA chemistry-climate model is used to generate $\mathrm{BrO}$ and $\mathrm{O}_{3}$ fields for comparison with the MAX-DOAS measurements.

\section{Methods}

In this work, four local instruments at Eureka were used, including a passive DOAS instrument [Adams et al., 2012a], radiosondes, ozonesondes, and a cloud radar. The DOAS instrument site, the PEARL Ridge Lab, is located on Ellesmere Island, Nunavut, Canada $\left(86.4^{\circ} \mathrm{W}, 80.1^{\circ} \mathrm{N}\right), 610 \mathrm{~m}$ above sea-level, located near many fjords within the Canadian Arctic archipelago. During the 2011 Canadian Arctic ACE validation campaign [Adams et al., 2012b], DOAS BrO and oxygen dimer $\left(\mathrm{O}_{4}\right)$ measurements were made by the PEARL ground-based spectrometer (PEARL-GBS) from 10 March to 5 April 2011. To investigate the $\mathrm{BrO}$ recycling, aerosol profiles were retrieved from $\mathrm{O}_{4}$ measurements following the methods of Wagner et al. [2004] and Frieß et al. [2011].

Other local instruments were located near the Eureka Weather Station (10 m above sea-level, $15 \mathrm{~km}$ away from Ridge Lab). We provide an image (see Fig. 1) of the field site, showing the location of the MAX-DOAS instrument in relation to the Eureka Weather Station, as well as the viewing azimuth of the MAX-DOAS measurements. Typically, two radiosonde launches were made daily from the Eureka Weather Station during the campaign, recording vertical profiles of temperature, relative humidity, wind speed and direction. Ozonesondes were 
launched daily from 5-12 March 2011, and weekly from 17 March to 6 April, providing ozone profiles. The ozonesonde data have been corrected for non-standard solution volume and concentration, and normalized to a total ozone measurement (where available), with residual ozone interpolated from the 2011 MLS climatology [McPeters and Labow, 2012]. The uncertainty estimate is based on an analysis of known sources of electrochemical concentration cell (ECC) ozonesonde uncertainty, including pump rate, cell temperature, and radiosonde pressure errors, as well as background current correction and the corrections noted above (see Tarasick et al., 2015 for details). The uncertainty estimate is individual for each ozone profile, and agrees well on average with error profiles derived from field intercomparisons and laboratory studies [Kerr et al., 1994; Smit et al., 2007]. The Millimetre Cloud Radar (MMCR, Shupe et al. [2010]) was working 24 hours/day during the campaign, providing equivalent radar reflectivity, Doppler velocity, spectral width, and Doppler spectra, from which information about cloud height, thickness, internal structure and vertical motion can be determined.

\subsection{DOAS instrument and spectrum processing}

The PEARL-GBS is a Triax-180 crossed Czerny-Turner triple-grating UV-visible spectrometer, built by Instruments S.A./Jobin Yvon Horiba, with a thermoelectrically cooled charge-coupled device detector and a $0.5^{\circ}$ field-of-view [Fraser et al., 2009]. In this case study, the $1200 \mathrm{gr} / \mathrm{mm}$ grating was used, providing coverage from 320 to $400 \mathrm{~nm}$ with a fullwidth at half-maximum resolution of $\sim 0.45 \mathrm{~nm}$. The PEARL-GBS was installed under a custom-built suntracker [Adams, 2012] inside a UV-transparent acrylic dome. In order to measure tropospheric BrO, MAX-DOAS spectra were recorded from 320-400 nm at elevations of $6^{\circ}, 8^{\circ}, 10^{\circ}, 15^{\circ}, 30^{\circ}$, and $90^{\circ}$ (with the minimum viewing elevation angle restricted by railings on the roof). The time required for a full MAX-DOAS measurement sequence of six viewing elevation angles was about $15 \mathrm{~min}$. The azimuth angle of the suntracker was selected as $35^{\circ}$ clockwise from the north when performing the MAX-DOAS sequence. Sunlight arriving at the instrument from low elevation angles has typically taken a long path through the lower troposphere, making these measurements sensitive to the boundary layer. In contrast, in each MAX-DOAS elevation scan, the $90^{\circ}$ measurement of zenith-scattered light (ZSL-DOAS [Mount et al., 1987; Solomon et al., 1987; Platt and Stutz, 2008]) is primarily sensitive to stratospheric trace gases.

The observed spectra were analysed with the DOAS method [Platt and Stutz, 2008] 
implemented using QDOAS software [Danckaert et al., 2012]. ZSL-DOAS and MAX-DOAS spectra have been analysed with the settings shown in Table 1. The ZSL-DOAS spectra were analysed using daily noon reference spectra, and MAX-DOAS spectra were analysed using the $90^{\circ}$ elevation angle measurement within a scan sequence as the reference. Since ZSLDOAS and MAX-DOAS sample different regions of the atmosphere and hence different temperatures, the $223 \mathrm{~K}$ ozone cross section was used for the analysis of spectra from ZSLDOAS, while two ozone cross sections at $223 \mathrm{~K}$ and $243 \mathrm{~K}$ were used in the MAX-DOAS analysis to limit the systematic error due to the temperature dependence of the cross sections. This approach was only applied for ozone as it is a strong absorber present in both the stratosphere and troposphere. Two BrO fitting windows were selected: 337-361.9 nm (a wide fitting window containing four absorption lines, e.g., Hay, [2010]) for MAX-DOAS spectra and 345-359 $\mathrm{nm}$ (a smaller fitting window containing two absorption lines, e.g., Hendrick et al., [2007]) for zenith-sky spectra. The smaller wavelength region was used for the zenith-sky retrievals to avoid two strong absorption features between $337 \mathrm{~nm}$ and 341.5 $\mathrm{nm}$ from stratospheric ozone [Aliwell et al., 2002; Adams, 2012]. Note that the MAX-DOAS $\mathrm{O}_{4}$ fitting window was $335-367 \mathrm{~nm}$ (containing two $\mathrm{O}_{4}$ absorption features).

The output of QDOAS is differential slant column density (dSCD), which is the difference between the trace gas columns along the effective light paths of the analyzed spectrum and the reference spectrum. The MAX-DOAS dSCDs of $\mathrm{BrO}$ and $\mathrm{O}_{4}$ measured at Eureka from 15 April 2011 are shown in Fig. 2, along with root mean square (RMS) fitting residuals. In Fig. 2, from 4-5 April, the MAX-DOAS BrO dSCDs at different elevation viewing angles are well separated, characteristic of enhanced $\mathrm{BrO}$ in the lower atmosphere. The well-separated $\mathrm{O}_{4}$ dSCDs show that 5 April was a clear day, and so MAX-DOAS data should be of high quality on that day.

\subsection{DOAS profile retrievals}

The Optimal Estimation Method (OEM, Rodgers, [2000]) was used for both stratospheric and tropospheric BrO profile retrievals. As described in Sect. 2.1, the PEARL-GBS provided both ZSL-DOAS and MAX-DOAS data, enabling the retrieval of both stratospheric and tropospheric BrO. The MAX-DOAS data, from which we retrieved tropospheric aerosol extinction profiles, tropospheric $\mathrm{BrO}$ profiles, and $\mathrm{BrO}$ partial column densities, are sensitive to the boundary layer, and thus are more suitable for studying bromine explosion events. However, because the descent of stratospheric $\mathrm{BrO}$ has been suggested as a possible source 
for a false bromine explosion signal [Salawitch et al., 2010], the ZSL-DOAS data, which are sensitive to the stratosphere, were used to retrieve $\mathrm{BrO}$ stratospheric profiles and total vertical column densities (VCDs). Since the method for retrieving stratospheric BrO applied in this work has been described in detail by Schofield et al. [2004], and the method used for tropospheric $\mathrm{BrO}$ and aerosol retrievals has been described in Frieß et al. [2011], both methods are described only briefly here.

In the profile retrievals, a Radiative Transfer Model (RTM) is used as the forward model, $F(\boldsymbol{x}, \boldsymbol{b})$, to convert the number density profiles, $\boldsymbol{x}$, into measurement dSCDs, $\boldsymbol{y}$. The vector $\boldsymbol{b}$ represents additional forward model parameters (e.g., atmospheric pressure and temperature profiles from radiosondes) which are not retrieved. The weighting function matrix is given as

$$
\boldsymbol{K}=\frac{\partial F}{\partial x}
$$

and describes the sensitivity of the measured dSCDs to changes in the number density profiles. The OEM evaluates the agreement between the measured and calculated dSCDs, taking into account the error covariance matrices for the measurements, $\mathbf{S}_{\varepsilon}$, and that for the $a$ priori profile, $\mathbf{S}_{a}$. The averaging kernel matrix, $\mathbf{A}$, is calculated from the error covariance matrices and the weighting function as

$$
\mathbf{A}=\left(\mathbf{K}^{T} S_{\varepsilon}^{-1} \mathbf{K}+S_{a}^{-1}\right)^{-1} K^{T} S_{\varepsilon}^{-1} \mathbf{K}
$$

and $\mathbf{A}$ describes the sensitivity of the retrieved number density profiles $(\widehat{\boldsymbol{x}})$ to the true state of the atmosphere $(\boldsymbol{x})$.

For the stratospheric retrievals, we followed the method of Schofield et al. [2006]. In this work, a single scattering RTM was used as the forward model [Schofield, 2003]. The forward model is a spherical shell radiative transfer model, which includes refraction, Rayleigh scattering, Mie scattering, and molecular absorption. The forward model parameters of ozone, temperature and pressure were provided by ozonesonde measurements. The tropopause heights were derived by considering the available ozonesonde data. The diurnal variation of the vertical distribution of $\mathrm{BrO}$ adds complication to the retrieval, and this has been addressed by Schofield et al. [2006] and Hendrick et al. [2007] by incorporating a photochemical model in the forward modeling of the inversion problem. Therefore in our stratospheric retrievals, a chemical-climate model (UM-UKCA, details presented in Sect. 3.4) was used to define the a priori set of profiles. 
For the tropospheric retrievals, we followed a two-step approach for the retrieval of tropospheric aerosol and trace gas profiles from MAX-DOAS spectra [Frieß et al., 2011]. First, aerosol extinction profiles were retrieved from the measured $\mathrm{O}_{4}$ dSCDs in the lowermost $4 \mathrm{~km}$ of the atmosphere on a $250-\mathrm{m}$ vertical grid. In the second step, these aerosol extinction profiles served as a forward model parameter for the retrieval of $\mathrm{BrO}$ vertical profiles. The radiative transfer model SCIATRAN2 [Rozanov et al., 2005] and the Heidelberg remote sensing group retrieval code (an iterative nonlinear optimal estimation algorithm based on the Levenberg-Marquardt method) [Frieß et al., 2011] were used in this work for the tropospheric aerosol and $\mathrm{BrO}$ profile retrievals. As for the aerosol extinction profile retrievals, a vertical grid of $250-\mathrm{m}$ resolution for the lowermost $4 \mathrm{~km}$ of the atmosphere was used for the $\mathrm{BrO}$ profile retrievals. Use of a finer grid of $50 \mathrm{~m}$ or $100 \mathrm{~m}$ did not have a significant impact on the results.

The a priori $\mathrm{BrO}$ profile for MAX-DOAS profile retrievals was chosen as exponentially decreasing with altitude (with a scale height of $500 \mathrm{~m}$ or $1000 \mathrm{~m}$ depending on the condition of atmospheric stability: $500 \mathrm{~m}$ when a strong surface inversion was seen in the radiosonde data, $1000 \mathrm{~m}$ for a weak inversion layer), and the surface volume mixing ratio (VMR) was set to 5 pptv for 4-5 April and 1 pptv for 1-3 April. Like Peterson et al. [2015], we found that the retrieved $\mathrm{BrO}$ profiles were sensitive to the choice of scale height in the a priori profile, due to the limited degrees of freedom for signal (DOFS) in the MAX-DOAS retrieval. The diagonal elements of the a priori covariance matrix, $\mathbf{S}_{a}$, were set to twice the values of the $a$ priori VMR. The off-diagonal elements of the a priori covariance matrix were chosen to decrease exponentially with the distance between the layers (with a correlation length of 500 $\mathrm{m})$ to improve the smoothness of the retrieved BrO profiles [Frieß et al., 2011]. Except for the different vertical grid resolution and a priori profiles, other aspects of the MAX-DOAS profile retrievals in this work are identical to those of Frieß et al. [2011].

\subsection{Complementary datasets}

In addition to the instruments at Eureka (PEARL-GBS, ozonesondes, radiosondes, and MMCR), several other datasets were employed in this study: the Global Ozone Monitoring Experiment-2 (GOME-2) satellite tropospheric BrO columns [Begoin et al., 2010; Blechschmidt et al., 2015], the Hybrid Single-Particle Lagrangian Integrated Trajectory (HYSPLIT) model [Draxler and Hess, 1998; Draxler et al., 2014], the European Centre for Medium-Range Weather Forecasts (ECMWF) interim meteorological data (ERA-interim 
data) (wind speed, boundary layer height, and large-scale snow-fall) [Dee et al., 2011], the National Snow and Ice Data Center (NSIDC) data (sea-ice age and snow depth over sea-ice) [Kurtz et al., 2012], and the UM-UKCA chemistry-climate model [Morgenstern et al., 2009; Yang et al., 2014].

The GOME-2 data used in this paper are described in detail by Blechschmidt et al. [2015]. In short, tropospheric $\mathrm{BrO}$ partial columns ( $\left.\mathrm{VCD}_{\text {tropo }}\right)$ were obtained based on Begoin et al. [2010] for deriving total slant column densities of BrO using the DOAS method (336-347 nm fitting window; Afe et al., 2004) and on Theys et al. [2011] for stratospheric correction. Stratospheric vertical column densities of BrO were estimated using the Theys et al. [2011] climatology of stratospheric BrO from the BASCOE [Errera et al., 2008; Viscardy et al., 2010] chemical transport model and NCEP/NCAR Reanalysis 1 [Kalnay et al., 1996] thermal tropopause heights. A sensitivity study showed that the GOME- $2 \mathrm{VCD}_{\text {trop }}$ used in this study has a moderate sensitivity to the stratospheric $\mathrm{BrO}$ column assumed during the $\mathrm{BrO}$ event. $\mathrm{A}$ variation in the $\mathrm{VCD}_{\text {strat }}$ of $15-30 \%$ leads to a change in $\mathrm{VCD}_{\text {trop }}$ of about 0.5 to $1 \times 10^{13}$ molec $\mathrm{cm}^{-2}$, respectively. The BrO VCD trop doesn't vary much with time, as the stratospheric column only varies between about 2.9 to $3.4 \times 10^{13}$ molec $\mathrm{cm}^{-2}$ over the time period studied. Note that dynamical tropopause heights derived from Weather Research and Forecasting (WRF) [Skamarock et al., 2008] simulations are used in Blechschmidt et al. [2015] instead of NCEP tropopause heights. Comparison of the GOME-2 data used in the present study and the one by Blechschmidt et al. [2015] for the time period up to 2 April 2011 showed a minor effect of the different tropopause data on the data analysis. The influence of clouds on the GOME-2 BrO retrievals for the time period 31 March to 2 April 2011 and implications on studying the bromine explosion event using the GOME-2 data are discussed in detail in Blechschmidt et al. [2015].

To explore the history of the bromine-enriched airmass and the source region of the bromine explosion event, we examined the GOME-2 data along with HYSPLIT back-trajectories. Since bromine explosion events are known to occur in windy conditions over first-year sea ice regions [Abbatt et al., 2012], we also investigated the ERA-interim data and sea-ice information over the Beaufort Sea, including snow depth data from the Advanced Microwave Scanning Radiometer-Earth Observing System (AMSR-E) aboard the Aqua satellite [Comiso et al., 2003], and Arctic sea-ice age data from the NSIDC. 


\subsection{Chemistry-climate model}

UM-UKCA is a global chemistry-climate model; its dynamical core is the Met Office Unified Model (UM) version 7.3 running in the HadGEM3-A configuration [Morgenstern et al., 2009]. The UMUKCA-CheST version contains a comprehensive stratospheric chemistry scheme as well as a detailed tropospheric chemistry scheme, including isoprene chemistry. Tropospheric bromine chemistry was introduced based on the work in pTOMCAT [Yang et al., 2005; Yang et al., 2010]. The bromine source includes inorganic sea salt source from both the open ocean and the sea ice zone (from blowing snow [Yang et al., 2008]), and halocarbons from long-lived (e.g., $\mathrm{CH}_{3} \mathrm{Br}$ ) and very short-lived substances (VSLSs, e.g., $\mathrm{CHBr}_{3}$ and $\mathrm{CH}_{2} \mathrm{Br}_{2}$ ) based on Warwick et al. [2006]. The total amount of inorganic $\mathrm{Br}_{\mathrm{y}}$ (from both halocarbons and sea salt) in the stratosphere is about 20 pptv [Braesicke et al., 2013]. A number of heterogeneous reactions on atmospheric particles (including sulphate aerosols and polar stratospheric clouds) have been included in the model to account for inter-halogen (chlorine and bromine) reactivation as in the recent study by Braesicke et al. [2013] and Yang et al. [2014]. In the polar boundary layer, heterogeneous reactivation of inactive bromine on sulphate aerosols has been considered with sulphate field being monthly climatology data from the CLASSIC aerosol scheme [Johnson et al., 2010]. There are no other reactivations within the snowpack or on aloft snow particles included in this study. The model's horizontal resolution was $3.75^{\circ}$ in longitude and $2.5^{\circ}$ in latitude on an Arakawa-C grid. A hybrid sigma-geometric height coordinate was used to resolve the vertical range from the surface to $\sim 84 \mathrm{~km}$ on 60 levels.

\section{Results and discussion}

\subsection{BrO and aerosol vertical profiles}

For the stratospheric BrO profile retrievals, Fig. 3(a) shows the ZSL-DOAS measured and fitted BrO dSCDs on 4 April 2011 PM. The retrieved BrO profiles at various SZAs (which differ due to the strong diurnal variation of $\mathrm{BrO}$ ) on 4 April PM are shown in Fig. 3(b) along with the a priori profiles from the UM-UKCA chemistry-climate model hourly runs. The averaging kernels for this retrieval are a function of both altitude and time (SZA), which means each element of the state vector has a two-dimensional averaging kernel [Schofield et al., 2004]. The profile (at $74^{\circ} \mathrm{SZA}$ ) has DOFS of 1.75 . The averaging kernels (not shown) indicate that the retrieved profile is more sensitive to the stratosphere, and the tropospheric 
part of the retrieved profile is mostly determined by the a priori information. The shape and magnitude of the stratospheric $\mathrm{BrO}$ profiles before and during the bromine explosion event provides some insight into whether the descent of stratospheric $\mathrm{BrO}$ was the source of tropospheric $\mathrm{BrO}$ enhancement as discussed in Sect. 3.3.

As mentioned in Sect. 2, the tropospheric aerosol and $\mathrm{BrO}$ profiles were retrieved using MAX-DOAS data. First, we compared our aerosol extinction profiles with MMCR reflectivity data and local meteorological records at the Eureka Weather Station. Fig. 4 shows the direct comparison of MAX-DOAS aerosol extinction profiles with MMCR reflectivity profiles for the lowermost $4 \mathrm{~km}$ of the atmosphere. The MMCR data are more sensitive to cloud rather than fine aerosol particles, however, high values of extinction and reflectivity were consistently observed by the two instruments from 3-4 April 2011, indicating low visibility conditions (light falling snow is found in MMCR Doppler velocity data, not shown). In this blowing-snow-initialized event, cloud cover was observed from the surface to $\sim 3 \mathrm{~km}$ altitude by the MMCR. The meteorological record at the Eureka Weather Station (10 $\mathrm{m}$ above sea-level, $15 \mathrm{~km}$ away from PEARL) showed a combination of drifting snow, falling snow, and ice crystal conditions on 3-4 April. Meanwhile, the visibility was down to 1.5-4 $\mathrm{km}$, consistent with the MAX-DOAS aerosol extinction near surface being as high as $1.1 \mathrm{~km}^{-}$ 1 , corresponding to a visibility of about $3.5 \mathrm{~km}$. Fig. 4 shows that low aerosol extinction and low reflectivity were observed on 1 and 5 April, indicating clear-sky conditions on those days. The visibility record at the Eureka Weather Station was $15 \mathrm{~km}$ on 5 April, consistent with the MAX-DOAS aerosol extinction measurements $\left(\sim 0.2 \mathrm{~km}^{-1}\right)$. The clear-sky conditions on 5 April are ideal for the MAX-DOAS BrO profile retrievals [Frieß et al., 2011].

Averaging kernels for MAX-DOAS aerosol extinction and BrO profile retrievals on 4 and 5 April PM are shown in Fig. 5. The averaging kernels for the aerosol retrieval indicate higher sensitivity to upper layers during clear-sky conditions (5 April) than during low visibility conditions (4 April), consistent with the results in Frieß et al. [2011]. Since the averaging kernels for the $\mathrm{BrO}$ retrieval show little sensitivity above $2 \mathrm{~km}$ especially under low visibility conditions, the retrieved mixing ratio above $2-3 \mathrm{~km}$ was constrained tightly to the a priori. The DOFS represent the number of independent pieces of information that can be retrieved from the MAX-DOAS measurements. Due to the absence of near-horizon measurements in our MAX-DOAS scanning sequence $\left(6^{\circ}, 8^{\circ}, 10^{\circ}, 15^{\circ}\right.$, and $\left.30^{\circ}\right)$, the DOFS for BrO profile retrievals increased from 1.1 during low-visibility conditions on 4 April only to 1.5 in clear- 
sky conditions on 5 April. The DOFS in low-visibility conditions is similar to that reported by Frieß et al. [2011] (1.0), which indicate the retrieved MAX-DOAS profiles in the lowvisibility conditions are effectively just a scaling of the a priori profile. The clear-sky DOFS in this work is lower than reported by Frieß et al. [2011] and Peterson et al. [2015] (2.1 and 2.0 respectively), who both had scanning sequences of $1^{\circ}, 2^{\circ}, 5^{\circ}, 10^{\circ}$, and $20^{\circ}$. The retrieved MAX-DOAS BrO profiles are shown and discussed in detail in Sect. 3.4, along with the modeled BrO profiles.

\subsection{Comparison with GOME-2}

To assess the ground-based $\mathrm{BrO}$ measurements, we performed a comparison of retrieved DOAS BrO columns with GOME-2 BrO tropospheric vertical column density ( $\left.\mathrm{VCD}_{\text {tropo }}\right)$. The ground-based $\mathrm{VCD}_{\text {tropo }}$ (not shown here) was generated by the integration of $\mathrm{BrO}$ profiles using the 0-4 $\mathrm{km}$ altitude profiles from MAX-DOAS and 4-8 $\mathrm{km}$ from ZSL-DOAS. The two DOAS measurements generally sample different airmasses, with the combined tropospheric product having a horizontal sampling distance of less than $20 \mathrm{~km}$, which is more local than GOME-2. Thus only the satellite pixels over Eureka (approximately within a distance of $45 \mathrm{~km}$ from Eureka) were used in the comparison.

During the bromine explosion event, the $4-8 \mathrm{~km}$ partial columns only contribute $1-4 \%$ of the ground-based $\mathrm{BrO} \mathrm{VCD}_{\text {tropo }}$ (note that due to the limited vertical sensitivity at these altitudes, this contribution consists of a priori information). Therefore, in Fig. 6, the GOME-2 BrO $\mathrm{VCD}_{\text {tropo }}$ products are directly compared with the MAX-DOAS 0-4 km partial columns. Fig. 6a shows the GOME-2 $\mathrm{BrO} \mathrm{VCD}_{\text {tropo }}$ (approximately $0-8 \mathrm{~km}$ partial column, with the tropopause heights used in the satellite retrieval adapted from NCEP/NCAR Reanalysis 1 data) and the MAX-DOAS 0-4 km partial columns on 4-5 April 2011 agreed within error bars during the days with enhanced BrO. Fig. 6b shows GOME-2 versus MAX-DOAS BrO $\mathrm{VCD}_{\text {trop }}$ with $100 \mathrm{~min}$ coincident criterion for five days of measurements. The weighted linear regression accounting for MAX-DOAS and GOME-2 measurement errors indicates that GOME-2 measurements are highly correlated $(\mathrm{R}=0.79)$ with the MAX-DOAS measurements with a slope of 1.02 and offset of $7.0 \times 10^{12}$ molec $\mathrm{cm}^{-2}$. Changing the coincident time to $20 \mathrm{~min}$ provides comparable results with $\mathrm{R}=0.74$, but with fewer coincident measurements (14 vs. 9).

The retrieval errors for the ground-based and satellite DOAS $\mathrm{BrO}$ measurements on a clear 
day (5 April 2011) are smaller than those under low visibility conditions (4 April 2011); the ground-based MAX-DOAS BrO partial column density mean retrieval error on 5 April 2011 was $11.1 \%$, while the error on 4 April 2011 was $21.6 \%$. In general, the MAX-DOAS retrieval errors (statistical dSCD error, a priori error, and retrieved VCD error) are consistent with those of Frieß et al. [2011].

\subsection{The history of the bromine explosion event}

The air-mass history related to the local $\mathrm{BrO}$ enhancement at Eureka can be examined based on the analysis of back-trajectories and model results. In Fig. 7, HYSPLIT six-day backtrajectories ending at Eureka at 00:00 UTC on 4 April 2011 are shown at six different altitudes $(100 \mathrm{~m}, 600 \mathrm{~m}, 1 \mathrm{~km}, 2 \mathrm{~km}, 3 \mathrm{~km}$, and $4 \mathrm{~km})$. The back-trajectories confirmed that the high BrO airmass observed at Eureka on 4 April was over the Beaufort Sea on 31 March 2011. In addition, the trajectories showed a strong uplift of the lower tropospheric air to the middle troposphere inside the cyclone from 31 March to 1 April, consistent with the vertical transport of boundary layer bromine up to the free troposphere by frontal lifting described in Blechschmidt et al. [2015].

Blechschmidt et al. [2015] investigated the meteorological conditions during this bromine explosion event over the Beaufort Sea observed by GOME-2 and concluded that the bromine plume was most likely confined to the lowest $3 \mathrm{~km}$ of the atmosphere from 31 March to 2 April. Maps of GOME-2 tropospheric BrO from 29 March to 4 April 2011 (see Fig. 8) suggest that a bromine-enriched cyclone was generated on 31 March (the cyclone itself arrived at the Beaufort Sea on $30 \mathrm{March}$ ), and then moved eastward and passed over Eureka during the next four to five days. While the maximum $\mathrm{BrO} \mathrm{VCD}_{\text {trop }}$ decreased from $\sim 1.5 \times 10^{14}$ molec $\mathrm{cm}^{-2}$ (31 March) to $\sim 7 \times 10^{13}$ molec $\mathrm{cm}^{-2}$ (4 April) when the plume arrived at Eureka, it still exceeded the background $\operatorname{BrO} \operatorname{VCD}_{\text {trop }}\left(1-2 \times 10^{13} \mathrm{molec}^{-2}\right)$.

Fig. 9a shows that the bromine explosion event source region over the Beaufort Sea was covered by first-year sea ice during the third week of March, while Fig. 9b shows that the same region was also covered by deep snow $(\sim 25-35 \mathrm{~cm})$ from 31 March to 4 April. The 10metre wind gust and boundary-layer height from ERA-interim data are used to investigate the meteorological conditions in the bromine explosion source region. The ERA-interim data show that on 1 April, the wind speed in the cyclone increased to $24 \mathrm{~m} \mathrm{~s}^{-1}$ (Fig. 10a), and the boundary layer height increased to $800 \mathrm{~m}$ (Fig. 10b). This is strong enough to lift salty snow 
particles into the air [Jones et al., 2009] and accelerate multiphase chemical reactions (R1R4) on them to release bromine [Yang et al., 2008; Yang et al., 2010]. This is discussed in detail in Section 3.4. The size of airborne snow grains could change by sedimentation and sublimation processes during the transport, and these processes could produce small aerosol particles, which can be lifted to higher altitudes and transported over larger distances [Pomeroy et al., 1997]. Choi et al. [2012] show a similar comma-shaped bromine plume (maximum BrO VCD trop $\sim 8 \times 10^{13}$ molec $\mathrm{cm}^{-2}$ ) with wind speed $(\sim 9 \mathrm{~m} / \mathrm{s})$ on 19 April 2008 over the Chukchi Sea with an increased boundary layer height to $500 \mathrm{~m}$ and a weak surface temperature inversion. The strength of the low-pressure system in the present study is stronger than the one reported by Choi et al. [2012], which makes the deep vertical mixing and long-range transport more likely. When the bromine plume arrived over Eureka on 3-4 April, high aerosol extinction values were also observed by MAX-DOAS (see Fig. 4). Thus the sea salt aerosol could play an important role in this event, contributing to the persistence of the bromine plume for $\sim$ six days (from 31 March to 5 April), while it was transported eastward for $\sim 1,800 \mathrm{~km}$.

ERA-interim data and radiosondes indicated that the tropopause height at Eureka decreased from $\sim 8.5 \mathrm{~km}$ to $\sim 7 \mathrm{~km}$ with the arrival of this low-pressure system. Low-pressure systems are known to contribute to the transport of BrO plumes over large distances [Begoin et al., 2010]. We also investigated the cloud information (not shown here) from the Moderate Resolution Imaging Spectroradiometer (MODIS). The cloud images show that the front arrived late on 3 April at Eureka, which is consistent with the MAX-DOAS and satellite BrO retrievals shown in Fig. 6. MODIS images further indicate that the front either passed or dispersed during the following two days, while the measured tropospheric $\mathrm{BrO}$ levels were still high over Eureka.

During the days when the bromine plume was passing over Eureka, no evidence for the intrusion of stratospheric $\mathrm{BrO}$ into the free troposphere was found. As described in Sect. 3.2, the $4-8 \mathrm{~km}$ BrO partial column only contributed $\sim 1-4 \%$ of the $\mathrm{BrO} \mathrm{VCD}_{\text {trop }}$ during this time (comprised of a priori information). Ozonesonde profiles in Fig. 11 show that stratospheric ozone (ozone VMR $>100 \mathrm{ppbv}$ ) descended from $\sim 8 \mathrm{~km}$ to $\sim 7 \mathrm{~km}$ on 4 and 6 April, consistent with a small decrease in the tropopause height. The relative humidity profiles measured by radiosondes from 1-6 April also indicated no stratospheric intrusions (characterized by very low relative humidity) into the troposphere (Fig. 12). Fig. 12 (a, b) shows that the 
temperature profiles were strongly inverted in the lowest $\sim 500 \mathrm{~m}$ both before and after the bromine explosion event, but that the inversion weakened from 3-4 April when the wind speed increased $\left(7 \mathrm{~m} \mathrm{~s}^{-1}\right)$. The high wind conditions favored the destruction of the surface inversion layer over Eureka from 3-4 April, thus the boundary layer was not stable, consistent with the potential temperature profiles in Fig. 12 (c, d). This reduction of atmospheric stability over Eureka is the result of the cyclone and its much higher wind speed $\left(24 \mathrm{~m} \mathrm{~s}^{-1}\right.$ over the Beaufort Sea), and was involved in the vertical distribution of the $\mathrm{BrO}$ plume from the surface to $\sim 2 \mathrm{~km}$ altitude (details are discussed in Sect. 3.4.2). The role of wind speed and near-surface temperature in BrO vertical mixing is also reported by Peterson et al. [2015].

In summary, this bromine explosion event observed at Eureka during relatively low wind speeds was initiated by strong winds in a cyclone over the Beaufort Sea, and the transported bromine plume was subsequently coupled to local production/recycling over Eureka under stable shallow boundary layer conditions (this is further discussed in Sect. 3.4.2).

\subsection{Comparison with a chemistry-climate model}

In this work, we used the nudged version of the UM-UKCA model, which was driven by ERA-interim data. Fig. 13 shows the modeled tropospheric BrO column over the Arctic region from 30 March to 6 April 2011. The model captured the bromine plume, which was generated over the Beaufort Sea on 30 March and also its propagation towards Eureka in the following days, although the maximum modeled $\operatorname{BrO} \operatorname{VCD}_{\text {trop }}\left(\sim 9 \times 10^{13}\right.$ molec $\left.\mathrm{cm}^{-2}\right)$ over the Beaufort Sea was not as large as that observed by GOME-2 $\left(\sim 1.5 \times 10^{14} \mathrm{molec} \mathrm{cm}^{-2}\right)$. In particular, the measured and modeled vertical profiles of $\mathrm{BrO}$ over Eureka have been compared for the first time, and despite the differences in timing and absolute concentrations, the general features of this bromine explosion are captured by the model, especially the height of both the BrO layer and the ozone-depleted layer.

\subsubsection{Ozone vertical profile comparison}

To evaluate the model, we first compared the modeled ozone profiles with ozonesonde measurements. One strong surface ozone depletion event was found in both the observations and the model on 4-6 April 2011. Fig. 11 shows the ozone profiles over Eureka from ozonesonde measurements and the UM-UKCA model. The model underestimates the boundary layer ozone over Eureka on 25 and 27 March before the ozone depletion event occurred. However, on 4 April, measured ozone was depleted to 0.5-1.3 ppbv from 10-720 m 
altitude at 6:52 AM UTC, and the modeled surface ozone VMR at 7:00 AM UTC also dropped to $\sim 1 \mathrm{ppbv}$ for the lowermost $400 \mathrm{~m}$. The UM-UKCA model captured the whole bromine explosion event in this period with one-hour time resolution, revealing that the surface ozone depletion (Fig. 14a) was associated with the surface bromine surge (Fig. 14b). In the modeled ozone profiles shown in Fig. 14a, the surface ozone depletion over Eureka starts during 3 April, and lasts for the next three days, which is consistent with the low surface ozone measured by ozonesondes on 4 and 6 April (see Fig. 11).

\subsubsection{BrO vertical profile comparison}

The tropospheric BrO profiles retrieved by applying the OEM to our MAX-DOAS data as described in Section 2.2 reveal that a bromine plume was over Eureka from late on 3 April to 5 April (see Fig. 15a). The UM-UKCA model BrO is compared on the same colour scale in Fig. 15b. The modeled BrO also shows an increase from 3 to 5 April with similar temporal and spatial structure to that of the measured plume. Fig. 16 shows scatter plots of UM-UKCA model BrO partial columns (0-4 km) versus MAX-DOAS measurements. The MAX-DOAS data are hourly averages for the same time bins as the model. The model shows the best agreement with measurements on 4 April, with fitted slope $=0.84$ and $\mathrm{R}=0.75$ (see Fig. 15c). However, the modeled bromine explosion event started a half day earlier than seen in the observations (see Fig. 15b). On 5 April, the modeled $\mathrm{BrO}$ decreased faster than the measurements; when the latter still showed $\sim 20$ pptv BrO VMR in the boundary layer, the model value dropped to $\sim 5$ pptv (see Fig. 15d). However in general, the bromine explosion event initialized by blowing snow over the Beaufort Sea was captured by the UM-UKCA model.

Although UV-visible DOAS measurements are sensitive to the visibility and Frieß et al. [2011] reported that MAX-DOAS measurements could overestimate $\mathrm{BrO}$ concentration during low visibility events (surface aerosol extinction $>0.5 \mathrm{~km}^{-1}$ ), our case study shows BrO

enhancements under both clear (surface aerosol extinction $\sim 0.1 \mathrm{~km}^{-1}$ ) and low visibility (surface aerosol extinction $\sim 0.6 \mathrm{~km}^{-1}$ ) conditions (see Fig. 4). Moreover, the comparison between the ground-based and GOME-2 satellite $\mathrm{BrO} \mathrm{VCD}_{\text {trop }}$ shows good consistency during those five days, giving confidence in the magnitude of the measured BrO. Taking all of these factors into consideration, the model clearly underestimated the BrO concentration.

To investigate the difference between the model and measurements, a sensitivity experiment 
with two different calculations for bromine release fluxes in the UM-UKCA model was implemented (see Fig. 14). The bromine release fluxes were calculated by a complex function of the sea-salt bromine depletion factor, wind speed at $10 \mathrm{~m}$, air temperature, relative humidity, snow age, and snow salinity [Yang et al., 2008]. In the high bromine release flux run, a larger sea-salt bromine depletion factor was selected, following Breider et al. [2010]; and in the low bromine release flux run, a smaller sea-salt bromine depletion factor was selected, following Yang et al. [2008]. These two factors were derived from the same field observations dataset compiled by Sander et al. [2003], and the difference was caused by the limited total number of samples in the dataset (the higher factor is the median value of the factors in the samples; the smaller factor is the mean value). The difference in the sea-salt depletion factors thus resulted in a difference in bromine release fluxes from sea salt by a factor of 2-3 in the source region [Yang et al., 2010].

In Fig. 14, the modeled ozone and BrO profiles from 1-6 April 2011 are compared. As seen in the first row of the figure (Fig. 14a and d), the ozone profiles look similar for these two model runs using low and high bromine fluxes. Unexpectedly, the model results using the high bromine flux run did not produce 2-3 times larger surface BrO VMR values compared to the low bromine flux run (see Fig. 14b and e), but instead revealed an "uplift" of the very high value $\mathrm{BrO}$ plume ( $\sim 30 \mathrm{pptv})$ in the upper boundary layer; and a reduction in $\mathrm{BrO}(<5$ pptv) below that height $(\sim 600 \mathrm{~m})$ (see Fig. 14e). In the high flux run, more bromine was initially introduced into the system, resulting in lower ozone concentrations, while the stable boundary layer limited the dynamical entrainment of ozone-rich air from aloft into the boundary layer. Thus BrO production through reaction R3 was lowest during these near-zero ozone concentrations in the boundary layer and caused the decreased surface BrO VMR (compared to the low bromine flux run), similar to another case observed in Barrow by Helmig et al. [2012]. To show this more clearly, Fig. 14c and Fig. 14f show ozone profiles with a 1 ppbv mask applied.

The sensitivity experiment reveals that the surface ozone depletion is more severe in the high bromine release flux run than in the low flux run, while the surface $\mathrm{BrO}$ is a result of a complex combination of local photochemistry (related to the ozone as well as $\mathrm{BrO}$ production and loss) and boundary layer dynamics (for example, wind pumping over the snowpack, venting and mixing of chemical compounds through the boundary layer, and varying boundary layer height). The sensitivity experiment and ozonesonde data reveal that this 
bromine explosion event was accompanied by very low concentrations of ozone, which complicates the relationship between total reactive halogen production $\left(\mathrm{BrO}_{\mathrm{x}}=\mathrm{Br}+\mathrm{BrO}\right)$ and $\mathrm{BrO}$. For this reason, in the absence of more frequent ozonesonde measurements and/or more intensive modeling, it is difficult to achieve quantitative agreement between the $\mathrm{BrO}$ peak mixing ratio observed by MAX-DOAS and that modeled. The fastest loss of $\mathrm{BrO}$ is by photolysis, which varies diurnally, and when ozone is relatively high, the fastest loss of $\mathrm{Br}$ is via reaction $\mathrm{R} 3$. The break-even point where half of $\mathrm{BrO}_{\mathrm{x}}$ is present as $\mathrm{BrO}$ is a few ppbv of ozone, and is also dependent on the photolysis rate $\mathrm{J}_{\mathrm{BrO}}$. Thus, at 1 ppbv $\mathrm{O}_{3}$ or less, most of the reactive halogens are not $\mathrm{BrO}$ and the amount of $\mathrm{BrO}$ is highly sensitive to the actual $\mathrm{O}_{3}$ level, which is only observed twice per day in this study. $\mathrm{BrO}$ is also sensitive to $\mathrm{J}_{\mathrm{BrO}}$, and the data on Fig. 15 show morning and afternoon peaks of $\mathrm{BrO}$ with a near-noon dip on 4 and 5 April. That could be due to increased $\mathrm{J}_{\mathrm{BrO}}$ near noon partitioning $\mathrm{BrO}_{\mathrm{x}}$ away from $\mathrm{BrO}$. In general, when ozone mixing ratios are high (a few pbbv), $\mathrm{BrO}$ is a robust indicator of halogen activation and is less dependent on the amount of ozone present. However, for the case observed here, with very little ozone, infrequent measurements, and varying solar illumination, it is difficult for the model to capture the measured $\mathrm{BrO}$. The meteorology also plays an important role in the vertical distributions of $\mathrm{BrO}$ and ozone in the Arctic [Stutz et al., 2011; Peterson et al., 2015], creating an additional challenge for accurate modeling of BrO.

The differences between the model and measurements may also be due to several other factors. First, the horizontal sampling length of MAX-DOAS is dependent on wavelength and aerosol optical thickness, but we can estimate its spatial coverage based on simple geometric considerations. In this case study, the bromine layer extended to approximately $2 \mathrm{~km}$ and the lowest viewing elevation angle was $6^{\circ}$, and thus the MAX-DOAS effective spatial sampling was within $20 \mathrm{~km}$ (as discussed in Sect. 3.2). However, the model grid box near Eureka was about $72 \mathrm{~km} \times 278 \mathrm{~km}\left(3.75^{\circ}\right.$ longitude $\times 2.5^{\circ}$ latitude $)$. So the model output was an average of the BrO VMR over a much larger area than either the ground-based or satellite (GOME- 2 footprint size was about $40 \mathrm{~km} \times 80 \mathrm{~km}$ ) measurements. Second, the UM-UKCA model's primary BrO source was mainly driven by wind speed, however, Fig. 12 shows that 5 April was a calm day. In Fig. 12, the Eureka radiosonde data reveal a breakdown of the surface temperature inversion from 3-4 April and also show a recovery of the surface temperature inversion and calm wind conditions from 5-6 April. The ERA-interim data show that the daytime boundary layer heights at Eureka dropped from $450 \mathrm{~m}$ to $200 \mathrm{~m}$ throughout 4-6 April 
(not shown here). Thus during these calm conditions on 5-6 April, a stable shallow boundary layer ( $\sim 200 \mathrm{~m}$ during daytime) formed. The combination of the transported bromine and favorable meteorological conditions near Eureka triggered local activation or recycling of bromine. This is supported by the prolonged lifetime of the bromine explosion in the observations (surface ozone depletion lasted to the end of 6 April, as observed by ozonesondes) compared to the model prediction on 5-6 April. Also, when the bromine plume entered the Canadian archipelago, the wind speeds decreased, which could cause increased sedimentation of saline aerosol on tundra snowpack, potentially enhancing the bromine regeneration scheme proposed by Pratt et al. [2013] and Toyota et al. [2014]. However, none of these regeneration or recycling mechanisms are currently included in the chemical model. The modeled BrO has a clear diurnal cycle from 1 to 3 April. However this diurnal variation disappeared from 4 to 5 April due to the arrival of the bromine plume. The high nighttime BrO VMR on 4 and 5 April was the result of transport.

In general, the model was able to simulate this bromine explosion event initiated by blowing snow and subsequently subjected to long-range transport. The differences between the model and measurements indicate that this event was not a simple case of transportation of a bromine plume, but was a combination of transportation and two different local recycling mechanisms for bromine. The first recycling mechanism involves airborne saline aerosol on low visibility days (which explains the high BrO VMR measurements relative to the modeled BrO on 3-4 April), and the second one involves shallow stable boundary layer conditions over surface snow or sea-ice on calm clear days (which explains the prolonged lifetime of the bromine explosion event in the observations compared to the model on 5 April). This work supports the idea of Jones et al. [2009] that two sets of environmental conditions favour ODEs: high wind/blowing snow and low wind/stable boundary layer. Furthermore, this work demonstrates that both blowing snow and stable boundary layer mechanisms should be included in halogen-related chemistry-climate models.

\section{Conclusions}

This work presented a bromine explosion event observed on 3 to 5 April 2011 at Eureka, Canada by ground-based and satellite instruments. This event involved transportation of a bromine plume $\sim 1800 \mathrm{~km}$ from the Beaufort Sea over three days with evidence of "unusual" (not a stable shallow boundary layer) meteorological conditions at the bromine source. During the initial formation of the bromine explosion, a strong cyclone developed over the 
Beaufort Sea, and the boundary layer height increased to three times its background level. Tropospheric and stratospheric $\mathrm{BrO}$ profiles and partial column densities at Eureka were retrieved from ground-based MAX-DOAS and ZSL-DOAS data. The DOAS BrO profiles, ozonesonde data, and radiosonde data reveal no evidence of a stratospheric intrusion over Eureka during the event. MAX-DOAS aerosol extinction profiles and MMCR reflectivity data indicate that this bromine explosion event was observed at Eureka during both blowing snow and clear weather conditions. The MAX-DOAS tropospheric partial columns show good consistency with GOME-2 satellite data.

The UM-UKCA chemistry-climate model successfully reproduced some of the main features (such as the vertical structure of the bromine plume) of this bromine explosion event after including a bromine source from blowing snow related to sea-salt production. The modeled ozone profiles on 4 and 6 April 2011 are consistent with ozonesonde data. Comparison between the model and measurements indicates that surface $\mathrm{BrO}$ is not only controlled by photochemistry, but also by local dynamics, which also influence ozone through vertical mixing, indicating the difficulties in simulating $\mathrm{BrO}$ concentrations. Further study of local meteorological conditions reveals that the boundary layer stability could have a significant effect on the surface $\mathrm{BrO}$; a stable boundary layer may increase the likelihood of trapping a transported bromine plume and triggering local bromine release from the snowpack within the boundary layer, thus prolonging the duration of bromine explosion events, a process which is not currently included in chemical-climate models. This combination of observations and modelling confirms that both high wind/blowing snow and low wind/stable boundary layer are favourable environmental conditions for bromine explosion events, and in some cases, the combination of these two conditions will affect the lifetime of a bromine explosion event.

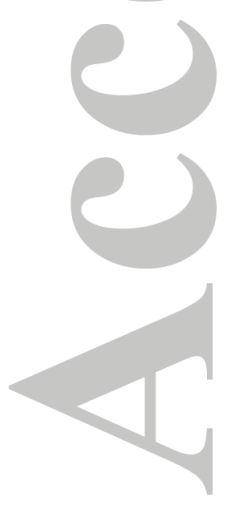




\section{Acknowledgements}

The authors gratefully acknowledge support from CANDAC funding agencies: ARIF, AIF/NSRIT, CFCAS, CFI, CSA, EC, GOC-IPY, INAC, NSERC, NSTP, OIT, ORF, PCSP, and SEARCH. We thank CANDAC/PEARL PI James R. Drummond, PEARL site manager Pierre Fogal, the CANDAC operators, and Environment Canada Eureka Weather Station staff for logistical and operational support at Eureka. The spring 2011 PEARL-GBS measurements were also supported by the Canadian Arctic ACE Validation Campaigns (Co-PI Kaley Walker), which were funded by Canadian Space Agency. The PEARL-GBS and MMCR data are available from CANDAC (http://www.candac.ca). The ozonesonde and radiosonde data for this paper are available through the Canadian Arctic ACE Validation Campaigns (http://acebox.uwaterloo.ca/eureka/Eureka2011/). Any additional data may be obtained from Xiaoyi Zhao (email: xizhao@atmosp.physics.utoronto.ca). X. Zhao is partially supported by the NSERC CREATE Training Program in Arctic Atmospheric Science. R. Schofield received funding support for this work from the Australian Research Councils Centre of Excellence (CE110001028) scheme. Ozonesonde, radiosonde, and MMCR measurements were proyided by David Tarasick, David Hudak, and Peter Rodriguez at Environment Canada. The QDOAS software and AMFs were provided by C. Fayt, F. Hendrick, and M. Van Roozendael at IASB-BIRA. Many thanks to Alexei Rozanov from IUP Bremen for providing the SCIATRAN radiative transfer model. We also want to thank Paul Telford and John Pyle at the University of Cambridge for supporting the UM-UKCA model integration. We thank the NSIDC, University of Colorado, the NOAA Air Resources Laboratory, and the ECMWF for providing datasets and models. NCEP Reanalysis data were provided by the NOAA/OAR/ESRL PSD, Boulder, Colorado. 


\section{References}

Abbatt, J. P. D., et al. (2012), Halogen activation via interactions with environmental ice and snow in the polar lower troposphere and other regions, Atmos. Chem. Phys., 12(14), 62376271 .

Adams, C. (2012), Measurements of atmospheric ozone, $\mathrm{NO}_{2}, \mathrm{OClO}$, and $\mathrm{BrO}$ at $80^{\circ} \mathrm{N}$ using UV-visible spectroscopy, Ph.D. thesis, University of Toronto.

Adams, C., et al. (2012a), Severe 2011 ozone depletion assessed with 11 years of ozone, $\mathrm{NO}_{2}$, and $\mathrm{OClO}$ measurements at $80^{\circ} \mathrm{N}$, Geophys. Res. Lett., 39(5), L05806, doi: $10.1029 / 2011 \mathrm{~g} 1050478$.

Adams, C., et al. (2012b), Validation of ACE and OSIRIS ozone and $\mathrm{NO}_{2}$ measurements using ground-based instruments at $80^{\circ} \mathrm{N}$, Atmos. Meas. Tech., 5(5), 927-953.

Afe, O. T., A. Richter, B. Sierk, F. Wittrock, and J. P. Burrows (2004), BrO emission from volcanoes: A survey using GOME and SCIAMACHY measurements, Geophys. Res. Lett., 31(24), L24113, doi: 10.1029/2004g1020994.

Aliwell, S., M. Van Roozendael, P. Johnston, A. Richter, T. Wagner, D. Arlander, J. Burrows, D. Fish, R. Jones, and K. Tørnkvist (2002), Analysis for BrO in zenith-sky spectra: An intercomparison exercise for analysis improvement, J. Geophys. Res., 107(D14), doi: doi:10.1029/2001JD000329.

Barrie, L. A., J. W. Bottenheim, R. C. Schnell, P. J. Crutzen, and R. A. Rasmussen (1988), Ozone destruction and photochemical-reactions at polar sunrise in the lower Arctic atmosphere, Nature, 334(6178), 138-141.

Begoin, M., A. Richter, M. Weber, L. Kaleschke, X. Tian-Kunze, A. Stohl, N. Theys, and J. P. Burrows (2010), Satellite observations of long range transport of a large BrO plume in the Arctic, Atmos. Chem. Phys., 10(14), 6515-6526.

Blechschmidt, A. M., A. Richter, J. P. Burrows, L. Kaleschke, K. Strong, N. Theys, M. Weber, X. Zhao, and A. Zien (2015), An exemplary case of a bromine explosion event linked to cyclone development in the Arctic, Atmos. Chem. Phys. Discuss., 15(17), 24955-24993.

Bogumil, K., et al. (2003), Measurements of molecular absorption spectra with the SCIAMACHY pre-flight model: instrument characterization and reference data for atmospheric remote-sensing in the $230-2380 \mathrm{~nm}$ region, J. Photochem. Photobiol. A, 157(23), 167-184.

Bottenheim, J. W., A. G. Gallant, and K. A. Brice (1986), Measurements of $\mathrm{NO}_{\mathrm{y}}$ species and $\mathrm{O}_{3}$ at $82^{\circ} \mathrm{N}$ latitude, Geophys. Res. Lett., 13(2), 113-116.

Braesicke, P., J. Keeble, X. Yang, G. Stiller, S. Kellmann, N. L. Abraham, A. T. Archibald, P. Telford, and J. A. Pyle (2013), Consistent circulation differences in the Southern Hemisphere caused by ozone changes: a chemistry-climate model and observational study, Atmos. Chem. Phys. Discuss., 13(3), 8455-8487.

Breider, T. J., M. P. Chipperfield, N. A. D. Richards, K. S. Carslaw, G. W. Mann, and D. V. Spracklen (2010), Impact of $\mathrm{BrO}$ on dimethylsulfide in the remote marine boundary layer, Geophys. Res. Lett., 37(2), L02807, doi: 10.1029/2009g1040868.

Chance, K. V., and R. J. D. Spurr (1997), Ring effect studies: Rayleigh scattering, including molecular parameters for rotational Raman scattering, and the Fraunhofer spectrum, Appl. 
Opt., 36(21), 5224-5230.

Choi, S., et al. (2012), Analysis of satellite-derived Arctic tropospheric BrO columns in conjunction with aircraft measurements during ARCTAS and ARCPAC, Atmos. Chem. Phys., 12(3), 1255-1285.

Comiso, J. C., D. J. Cavalieri, and T. Markus (2003), Sea ice concentration, ice temperature, and snow depth using AMSR-E data, IEEE Trans. Geosci. Remote Sens., 41(2), 243-252.

Danckaert, T., C. Fayt, M. van Roozendael, I. de Smedt, V. Letocart, A. Merlaud, and G. Pinardi (2012), QDOAS Software user manual.

Dee, D. P., et al. (2011), The ERA-Interim reanalysis: configuration and performance of the data assimilation system, Q. J. Roy. Meteor. Soc., 137(656), 553-597.

Dibb, J. E., L. D. Ziemba, J. Luxford, and P. Beckman (2010), Bromide and other ions in the snow, firn air, and atmospheric boundary layer at Summit during GSHOX, Atmos. Chem. Phys., 10(20), 9931-9942.

Draxler, R., and G. D. Hess (1998), An Overview of the HYSPLIT_4 modeling system for trajectories, dispersion and deposition, Aust. Met. Mag., 47, 295-308.

Draxler, R., R. Draxler, B. Stunder, G. Rolph, A. Stein, and A. Taylor (2014), HYSPLIT4 user's guide, report, NOAA, Silver Spring, MD. (Available at http://www.arl.noaa.gov/documents/reports/hysplit user_guide.pdf).

Errera, Q., F. Daerden, S. Chabrillat, J. C. Lambert, W. A. Lahoz, S. Viscardy, S. Bonjean, and D. Fonteyn (2008), 4D-Var assimilation of MIPAS chemical observations: ozone and nitrogen dioxide analyses, Atmos. Chem. Phys., 8(20), 6169-6187.

Fan, S.-M., and D. J. Jacob (1992), Surface ozone depletion in Arctic spring sustained by bromine reactions on aerosols, Nature, 359(6395), 522-524.

Fleischmann, O. C., M. Hartmann, J. P. Burrows, and J. Orphal (2004), New ultraviolet absorption cross-sections of $\mathrm{BrO}$ at atmospheric temperatures measured by time-windowing Fourier transform spectroscopy, J. Photochem. Photobiol. A, 168(1-2), 117-132.

Fogal, P. F., L. M. LeBlanc, and J. R. Drummond (2013), The Polar Environment Atmospheric Research Laboratory (PEARL): Sounding the Atmosphere at $80^{\circ}$ North, Arctic, 66(3), 337-386.

Fraser, A., C. Adams, J. R. Drummond, F. Goutail, G. Manney, and K. Strong (2009), The Polar Environment Atmospheric Research Laboratory UV-visible Ground-Based Spectrometer: First measurements of $\mathrm{O}_{3}, \mathrm{NO}_{2}, \mathrm{BrO}$, and $\mathrm{OClO}$ columns, J. Quant. Spectrosc. Radiat. Transfer, 110(12), 986-1004.

Frieß, U., J. Hollwedel, G. König-Langlo, T. Wagner, and U. Platt (2004), Dynamics and chemistry of tropospheric bromine explosion events in the Antarctic coastal region, $J$. Geophys.Res., 109(D6), D06305, doi: 10.1029/2003jd004133.

Frieß, U., H. Sihler, R. Sander, D. Pöhler, S. Yilmaz, and U. Platt (2011), The vertical distribution of $\mathrm{BrO}$ and aerosols in the Arctic: Measurements by active and passive differential optical absorption spectroscopy, J. Geophys. Res., 116(D14), D00R04, doi: $10.1029 / 2011 \mathrm{jd} 015938$.

Hay, T. D. (2010), MAX-DOAS measurements of bromine explosion events in McMurdo Sound, Antarctica, Ph.D. thesis, University of Canterbury. 
Helmig, D., et al. (2012), Ozone dynamics and snow-atmosphere exchanges during ozone depletion events at Barrow, Alaska, J. Geophys. Res., 117(D20), D20303, doi: 10.1029/2012jd017531.

Hendrick, F., et al. (2007), Retrieval of stratospheric and tropospheric BrO profiles and columns using ground-based zenith-sky DOAS observations at Harestua, $60^{\circ} \mathrm{N}$, Atmos. Chem. Phys., 7(18), 4869-4885.

Hermans, C., A. Vandaele, S. Fally, M. Carleer, R. Colin, B. Coquart, A. Jenouvrier, and M.F. Merienne (2003), Absorption cross-section of the collision-induced bands of oxygen from the UV to the NIR, in Weakly Interacting Molecular Pairs: Unconventional Absorbers of Radiation in the Atmosphere, edited by C. Camy-Peyret and A. A. Vigasin, Vigasin, Dordrecht, Netherlands, 193-202.

Hönninger, G., H. Leser, O. Sebastian, and U. Platt (2004), Ground-based measurements of halogen oxides at the Hudson Bay by active longpath DOAS and passive MAX-DOAS, Geophys. Res. Lett., 31(4), doi: 10.1029/2003GL018982.

Johnson, C., G. Mann, N. Bellouin, and M. Dalvi (2010), Comparison between UKCAMODE and CLASSIC aerosol schemes in HadGEM3, Integrated Climate Programme MOHC Report M3. 2 to DECC, report, March 2010. Technical report, Met Office.

Jones, A. E., P. S. Anderson, M. Begoin, N. Brough, M. A. Hutterli, G. J. Marshall, A. Richter, H. K. Roscoe, and E. W. Wolff (2009), BrO, blizzards, and drivers of polar tropospheric ozone depletion events, Atmos. Chem. Phys., 9(14), 4639-4652.

Kaleschke, L., et al. (2004), Frost flowers on sea ice as a source of sea salt and their influence on tropospheric halogen chemistry, Geophys. Res. Lett., 31(16), L16114, doi: 10.1029/2004g1020655.

Kalnay, E., M. Kanamitsu, R. Kistler, W. Collins, D. Deaven, L. Gandin, M. Iredell, S. Saha, G. White, and J. Woollen (1996), The NCEP/NCAR 40-year reanalysis project, B Am Meteorol Soc, 77(3), 437-471.

Kerr, J., H. Fast, C. McElroy, S. Oltmans, J. Lathrop, E. Kyro, A. Paukkunen, H. Claude, U. Köhler, and C. Sreedharan (1994), The 1991 WMO international ozonesonde intercomparison at Vanscoy, Canada, Atmos.-Ocean, 32(4), 685-716.

Koo, J. H., et al. (2012), Characteristics of tropospheric ozone depletion events in the Arctic spring: analysis of the ARCTAS, ARCPAC, and ARCIONS measurements and satellite $\mathrm{BrO}$ observations, Atmos. Chem. Phys., 12(20), 9909-9922.

Kurtz, N., M. S. Studinger, J. Harbeck, V. Onana, and S. Farrell (2012), IceBridge Sea Ice Freeboard, Snow Depth, and Thickness, Boulder, Colorado USA: NASA DAAC at the National Snow and Ice Data Center.

Lehrer, E., G. Hönninger, and U. Platt (2004), A one dimensional model study of the mechanism of halogen liberation and vertical transport in the polar troposphere, Atmos. Chem. Phys., 4(11/12), 2427-2440.

Liao, J., et al. (2011), A comparison of Arctic BrO measurements by chemical ionization mass spectrometry and long path-differential optical absorption spectroscopy, J. Geophys. Res., 116(D14), D00R02.

Liao, J., et al. (2012), Characterization of soluble bromide measurements and a case study of BrO observations during ARCTAS, Atmos. Chem. Phys., 12(3), 1327-1338. 
McConnell, J. C., G. S. Henderson, L. Barrie, J. Bottenheim, H. Niki, C. H. Langford, and E. M. J. Templeton (1992), Photochemical bromine production implicated in Arctic boundarylayer ozone depletion, Nature, 355(6356), 150-152.

McPeters, R. D., and G. J. Labow (2012), Climatology 2011: An MLS and sonde derived ozone climatology for satellite retrieval algorithms, J. Geophys. Res., 117(D10).

Morgenstern, O., P. Braesicke, F. M. O'Connor, A. C. Bushell, C. E. Johnson, S. M. Osprey, and J. A. Pyle (2009), Evaluation of the new UKCA climate-composition model - Part 1: The stratosphere, Geosci. Model Dev., 2(1), 43-57.

Mount, G. H., R. W. Sanders, A. L. Schmeltekopf, and S. Solomon (1987), Visible spectroscopy at memurdo station, Antarctica .1. Overview and daily variations of $\mathrm{NO}_{2}$ and $\mathrm{O}_{3}$, Austral Spring, 1986, J. Geophys. Res., 92(D7), 8320-8328.

Neuman, J. A., J. B. Nowak, L. G. Huey, and J. B. Burkholder (2010), Bromine measurements in ozone depleted air over the Arctic Ocean, Atmos. Chem. Phys., 10(14), 6503-6514.

Peterson, P. K., W. R. Simpson, K. A. Pratt, P. B. Shepson, U. Frieß, J. Zielcke, U. Platt, S. J. Walsh, and S. V. Nghiem (2015), Dependence of the vertical distribution of bromine monoxide in the lower troposphere on meteorological factors such as wind speed and stability, Atmos. Chem. Phys., 15(4), 2119-2137.

Platt, U., and J. Stutz (2008), Differential Optical Absorption Spectroscopy: Principles and Applications, Springer, Berlin.

Pomeroy, J. W., P. Marsh, and D. M. Gray (1997), Application of a distributed blowing snow model to the Arctic, Hydrological Processes, 11(11), 1451-1464.

Pratt, K. A., et al. (2013), Photochemical production of molecular bromine in Arctic surface snowpacks, Nature Geosci., 6(5), 351-356.

Rankin, A. M., E. W. Wolff, and S. Martin (2002), Frost flowers: Implications for tropospheric chemistry and ice core interpretation, J. Geophys. Res., 107(D23), doi: $10.1029 / 2002 \mathrm{jd} 002492$.

Richter, A., F. Wittrock, M. Eisinger, and J. P. Burrows (1998), GOME observations of tropospheric $\mathrm{BrO}$ in northern hemispheric spring and summer 1997, Geophys. Res. Lett., 25(14), 2683-2686.

Rodgers, C. D. (2000), Inverse Methods for Atmospheric Sounding : Theory and Practice, Series on Atmospheric, Oceanic and Planetary Physics, vol. 2, World Scientific, Singapore.

Rozanov, A., V. Rozanov, M. Buchwitz, A. Kokhanovsky, and J. P. Burrows (2005), SCIATRAN 2.0 - A new radiative transfer model for geophysical applications in the 175$2400 \mathrm{~nm}$ spectral region, Adv. Space Res., 36(5), 1015-1019.

Salawitch, R. J., et al. (2010), A new interpretation of total column BrO during Arctic spring, Geophys. Res. Lett., 37(21), L21805, doi: 10.1029/2010g1043798.

Sander, R., et al. (2003), Inorganic bromine in the marine boundary layer: a critical review, Atmos. Chem. Phys., 3(5), 1301-1336.

Schofield, R. (2003), The Vertical Distribution of Atmospheric BrO from Ground-Based Measurements, Ph.D. thesis, University of Auckland.

Schofield, R., K. Kreher, B. J. Connor, P. V. Johnston, A. Thomas, D. Shooter, M. P. 
Chipperfield, C. D. Rodgers, and G. H. Mount (2004), Retrieved tropospheric and stratospheric BrO columns over Lauder, New Zealand, J. Geophys. Res., 109(D14), D14304, doi: $10.1029 / 2003 j \mathrm{j} 004463$.

Schofield, R., et al. (2006), Tropospheric and stratospheric $\mathrm{BrO}$ columns over Arrival Heights, Antarctica, 2002, J. Geophys. Res., 111(D22), D22310, doi: 10.1029/2005jd007022.

Schroeder, W. H., K. G. Anlauf, L. A. Barrie, J. Y. Lu, A. Steffen, D. R. Schneeberger, and T. Berg (1998), Arctic springtime depletion of mercury, Nature, 394(6691), 331-332.

Shupe, M. D., V. P. Walden, E. Eloranta, T. Uttal, J. R. Campbell, S. M. Starkweather, and M. Shiobara (2010), Clouds at Arctic Atmospheric Observatories. Part I: Occurrence and Macrophysical Properties, J. Appl. Meteorol., 50(3), 626-644.

Sihler, H., et al. (2012), Tropospheric BrO column densities in the Arctic derived from satellite: retrieval and comparison to ground-based measurements, Atmos. Meas. Tech., 5(11), 2779-2807.

Simpson, W. R., D. Carlson, G. Hönninger, T. A. Douglas, M. Sturm, D. Perovich, and U. Platt (2007a), First-year sea-ice contact predicts bromine monoxide (BrO) levels at Barrow, Alaska better than potential frost flower contact, Atmos. Chem. Phys., 7(3), 621-627.

Simpson, W. R., et al. (2007b), Halogens and their role in polar boundary-layer ozone depletion, Atmos. Chem. Phys., 7(16), 4375-4418.

Skamarock, W., J. Klemp, J. Dudhia, D. Gill, D. Barker, M. Duda, X. Huang, W. Wang, and J. Powers (2008), NCAR Technical Note NCAR/TN--475+ STR: A Description of the Advanced Research WRF Version 3, Boulder, CO.

Smit, H. G., W. Straeter, B. J. Johnson, S. J. Oltmans, J. Davies, D. W. Tarasick, B. Hoegger, R. Stubi, F. Schmidlin, and T. Northam (2007), Assessment of the performance of ECC ozonesondes under quasi - flight conditions in the environmental simulation chamber: Insights from the Juelich Ozone Sonde Intercomparison Experiment (JOSIE), J. Geophys. Res., 112(D19).

Solomon, S., A. Schmeltekopf, and R. Sanders (1987), On the interpretation of zenith sky absorption measurements, J. Geophys. Res., 2(D7), 8311-8319.

Stutz, J., et al. (2011), Longpath DOAS observations of surface BrO at Summit, Greenland, Atmos. Chem. Phys., 11(18), 9899-9910.

Tarasick, D. W., J. Davies, H. G. J. Smit, and S. J. Oltmans (2015), A re-evaluated Canadian ozonesonde record: measurements of the vertical distribution of ozone over Canada from 1966 to 2013, Atmos. Meas. Tech. Discuss., 8(5), 5215-5264.

Theys, N., et al. (2011), Global observations of tropospheric BrO columns using GOME-2 satellite data, Atmos. Chem. Phys., 11(4), 1791-1811.

Toyota, K., J. C. McConnell, R. M. Staebler, and A. P. Dastoor (2014), Air-snowpack exchange of bromine, ozone and mercury in the springtime Arctic simulated by the 1-D model PHANTAS - Part 1: In-snow bromine activation and its impact on ozone, Atmos. Chem. Phys., 14(8), 4101-4133.

Vandaele, A. C., C. Hermans, P. C. Simon, M. Carleer, R. Colin, S. Fally, M. F. Mérienne, A. Jenouvrier, and B. Coquart (1998), Measurements of the $\mathrm{NO}_{2}$ absorption cross-section from $42000 \mathrm{~cm}^{-1}$ to $10000 \mathrm{~cm}^{-1}(238-1000 \mathrm{~nm})$ at $220 \mathrm{~K}$ and $294 \mathrm{~K}, J$. Quant. Spectrosc. Radiat. Transfer, 59(3-5), 171-184. 
Viscardy, S., Q. Errera, Y. Christophe, S. Chabrillat, and J. C. Lambert (2010), Evaluation of Ozone Analyses From UARS MLS Assimilation by BASCOE Between 1992 and 1997, Selected Topics in Applied Earth Observations and Remote Sensing, IEEE Journal of, 3(2), 190-202.

Vogt, R., P. J. Crutzen, and R. Sander (1996), A mechanism for halogen release from sea-salt aerosol in the remote marine boundary layer, Nature, 383(6598), 327-330.

Wagner, T., C. Leue, M. Wenig, K. Pfeilsticker, and U. Platt (2001), Spatial and temporal distribution of enhanced boundary layer $\mathrm{BrO}$ concentrations measured by the GOME instrument aboard ERS-2, J. Geophys. Res., 106(D20), 24225-24235.

Wagner, T., B. Dix, C. v. Friedeburg, U. Frieß, S. Sanghavi, R. Sinreich, and U. Platt (2004), MAX-DOAS $\mathrm{O}_{4}$ measurements: A new technique to derive information on atmospheric aerosols: Principles and information content, J. Geophys. Res., 109(D22), D22205, doi: 10.1029/2004jd004904.

Wahner, A., G. S. Tyndall, and A. R. Ravishankara (1987), Absorption cross sections for symmetric chlorine dioxide as a function of temperature in the wavelength range $240-480 \mathrm{~nm}$, J. Phys. Chem., 91(11), 2734-2738.

Warwick, N. J., J. A. Pyle, G. D. Carver, X. Yang, N. H. Savage, F. M. O'Connor, and R. A. Cox (2006), Global modeling of biogenic bromocarbons, J. Geophys. Res.: Atmospheres, $111(\mathrm{D} 24), \mathrm{D} 24305$.

Wennberg, P. (1999), Atmospheric chemistry: Bromine explosion, Nature, 397(6717), 299301.

Wren, S. N., D. Donaldson, and J. Abbatt (2013), Photochemical chlorine and bromine activation from artificial saline snow, Atmos Chem Phys, 13(19), 9789-9800.

Yang, X., J. A. Pyle, and R. A. Cox (2008), Sea salt aerosol production and bromine release: Role of snow on sea ice, Geophys. Res. Lett., 35(16), L16815, doi: 10.1029/2008g1034536.

Yang, X., J. A. Pyle, R. A. Cox, N. Theys, and M. Van Roozendael (2010), Snow-sourced bromine and its implications for polar tropospheric ozone, Atmos. Chem. Phys., 10(16), 77637773.

Yang, X., R. A. Cox, N. J. Warwick, J. A. Pyle, G. D. Carver, F. M. O'Connor, and N. H. Savage (2005), Tropospheric bromine chemistry and its impacts on ozone: A model study, $J$. Geophys. Res., 110(D23), D23311, doi: 10.1029/2005jd006244.

Yang, X., N. L. Abraham, A. T. Archibald, P. Braesicke, J. Keeble, P. J. Telford, N. J. Warwick, and J. A. Pyle (2014), How sensitive is the recovery of stratospheric ozone to changes in concentrations of very short-lived bromocarbons?, Atmos. Chem. Phys., 14(19), 10431-10438.

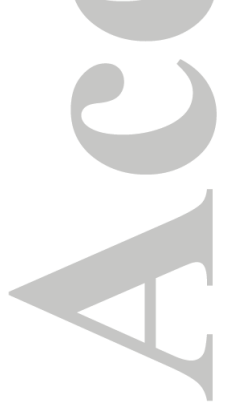




\begin{tabular}{|c|c|c|c|}
\hline & \multicolumn{2}{|c|}{ BrO } & \multirow{2}{*}{$\frac{\mathrm{O}_{4}}{\text { MAX-DOAS }}$} \\
\hline & MAX-DOAS & ZSL-DOAS & \\
\hline $\begin{array}{l}\text { BrO cross } \\
\text { section }\end{array}$ & $\begin{array}{c}\text { bro_223K_Fleischmann } \\
\text { (Fleischmann et al. } \\
\text { 2004) }\end{array}$ & $\begin{array}{c}\text { bro_223K_Fleischmann } \\
\text { (Fleischmann et al., } \\
\text { 2004) }\end{array}$ & $\begin{array}{c}\text { bro_223K_Fleischmann } \\
\text { (Fleischmann et al., } \\
\text { 2004) }\end{array}$ \\
\hline $\begin{array}{l}\mathrm{O}_{4} \text { cross } \\
\text { section }\end{array}$ & $\begin{array}{c}\text { Hermans } \\
\text { (Hermans et al., 2003) }\end{array}$ & $\begin{array}{c}\text { Hermans } \\
\text { (Hermans et al., 2003) }\end{array}$ & $\begin{array}{c}\text { Hermans } \\
\text { (Hermans et al., 2003) }\end{array}$ \\
\hline $\begin{array}{l}\mathrm{O}_{3} \text { cross } \\
\text { section }\end{array}$ & $\begin{array}{l}\text { O3_223_BOGUMIL } \\
\text { (Bogumil et al., 2003) }\end{array}$ & $\begin{array}{l}\text { O3_223_BOGUMIL } \\
\text { (Bogumil et al., 2003) }\end{array}$ & $\begin{array}{l}\text { O3_223_BOGUMIL } \\
\text { (Bogumil et al., 2003) }\end{array}$ \\
\hline $\begin{array}{l}\mathrm{O}_{3} \text { cross } \\
\text { section }\end{array}$ & $\begin{array}{l}\text { O3_243_BOGUMIL } \\
\text { (Bogumil et al., 2003) }\end{array}$ & $\mathrm{N} / \mathrm{A}$ & $\begin{array}{l}\text { O3_243_BOGUMIL } \\
\text { (Bogumil et al., 2003) }\end{array}$ \\
\hline $\begin{array}{l}\mathrm{NO}_{2} \text { cross } \\
\text { section }\end{array}$ & $\begin{array}{l}\text { NO2_220_VANDAELE } \\
\text { (Vandaele et al., 1998) }\end{array}$ & $\begin{array}{c}\text { NO2_220_VANDAELE } \\
\text { (Vandaele et al., 1998) }\end{array}$ & $\begin{array}{l}\text { NO2_220_VANDAELE } \\
\text { (Vandaele et al., 1998) }\end{array}$ \\
\hline $\begin{array}{l}\text { OClO cross } \\
\text { section }\end{array}$ & $\begin{array}{l}\text { OClO_Wahner_204K } \\
\text { (Wahner et al., 1987) }\end{array}$ & $\begin{array}{l}\text { OClO_Wahner_204K } \\
\text { (Wahner et al., 1987) }\end{array}$ & $\begin{array}{l}\text { OClO_Wahner_204K } \\
\text { (Wahner et al., 1987) }\end{array}$ \\
\hline $\begin{array}{c}\text { Ring } \\
\text { spectrum }\end{array}$ & $\begin{array}{c}\text { Ring } \\
\text { (Chance and Spurr, } \\
\text { 1997) }\end{array}$ & $\begin{array}{c}\text { Ring } \\
\text { (Chance and Spurr, } \\
\text { 1997) }\end{array}$ & $\begin{array}{c}\text { Ring } \\
\text { (Chance and Spurr, } \\
\text { 1997) }\end{array}$ \\
\hline Wavelength & $337-361.9 \mathrm{~nm}$ & $345-359 \mathrm{~nm}$ & $335-367 \mathrm{~nm}$ \\
\hline Polynominal & $4^{\text {th }}$ order & $3^{\text {rd }}$ order & $4^{\text {th }}$ order \\
\hline $\begin{array}{l}\text { Shift and } \\
\text { stretch }\end{array}$ & $1^{\text {st }}$ order & $1^{\text {st }}$ order & $1^{\text {st }}$ order \\
\hline Offset & $1^{\text {st }}$ order & $1^{\text {st }}$ order & $1^{\text {st }}$ order \\
\hline
\end{tabular}

Table 1. Settings used for MAX-DOAS and ZSL-DOAS spectral analysis. 

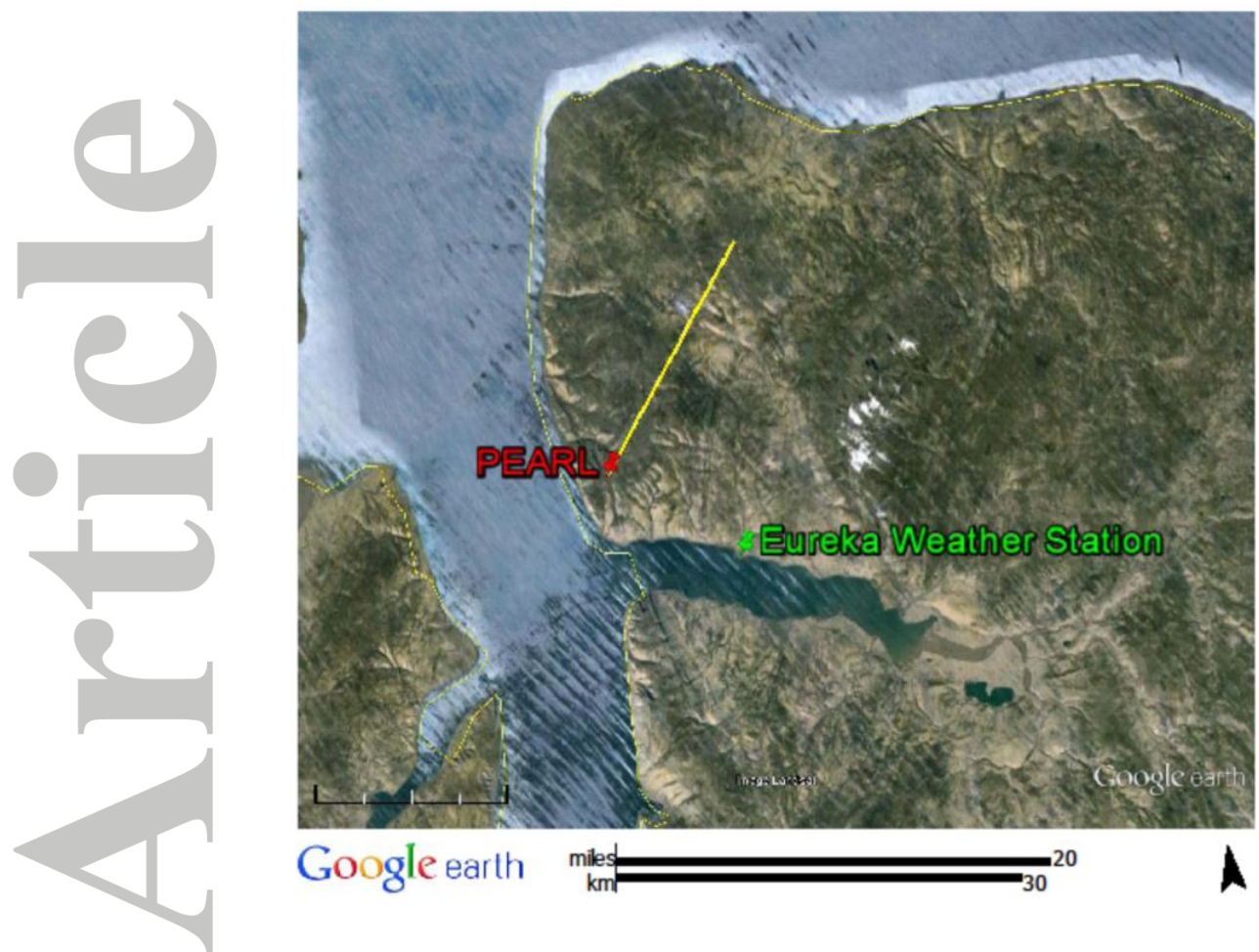

\section{Google earth}

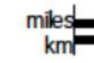

$\Lambda$

Fig. 1. Locations of Eureka Weather Station and PEARL Ridge Lab (map data: Google earth). The yellow line (20 km in length) represents the viewing azimuth direction of MAXDOAS measurements, which is $35^{\circ}$ from true north.

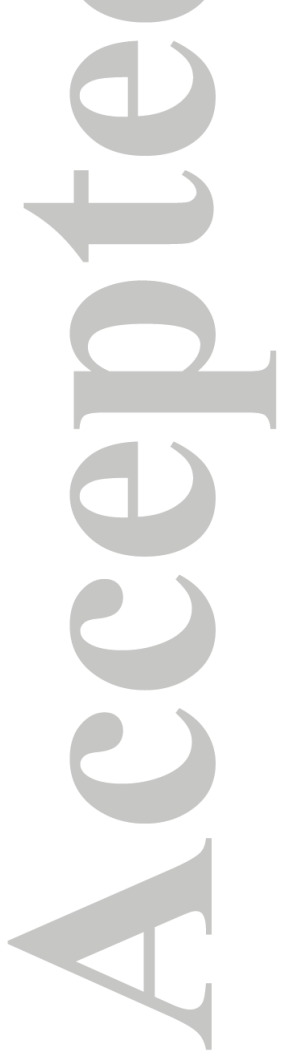



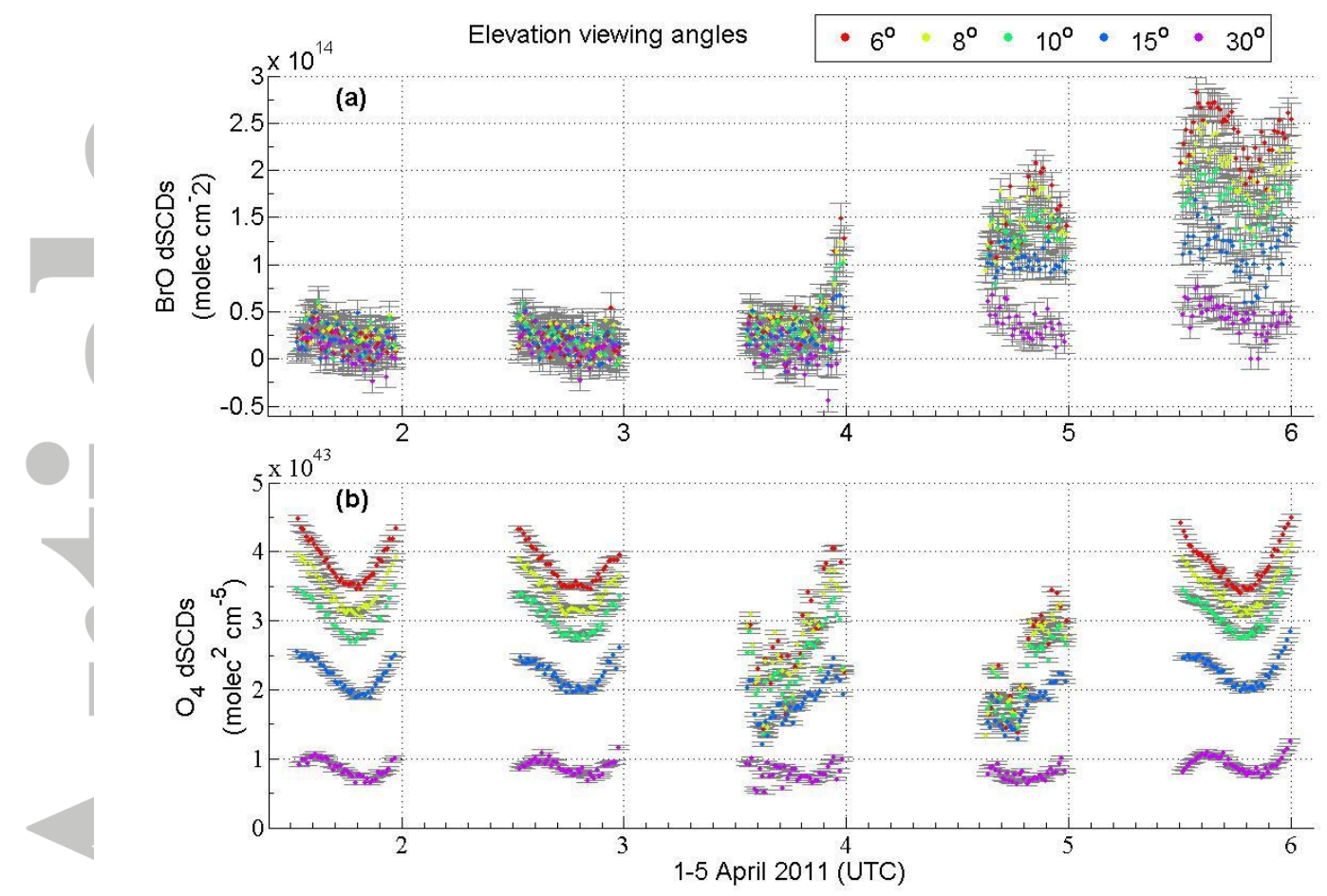

Fig. 2. MAX-DOAS dSCDs at different elevation viewing angles (indicated in legend) measured at Eureka from 1-5 April 2011. (a) BrO dSCDs with error bars; (b) $\mathrm{O}_{4}$ dSCDs with error bars. Note: These dSCDs are relative to the $90^{\circ}$ zenith spectrum for each MAX-DOAS scan sequence. 

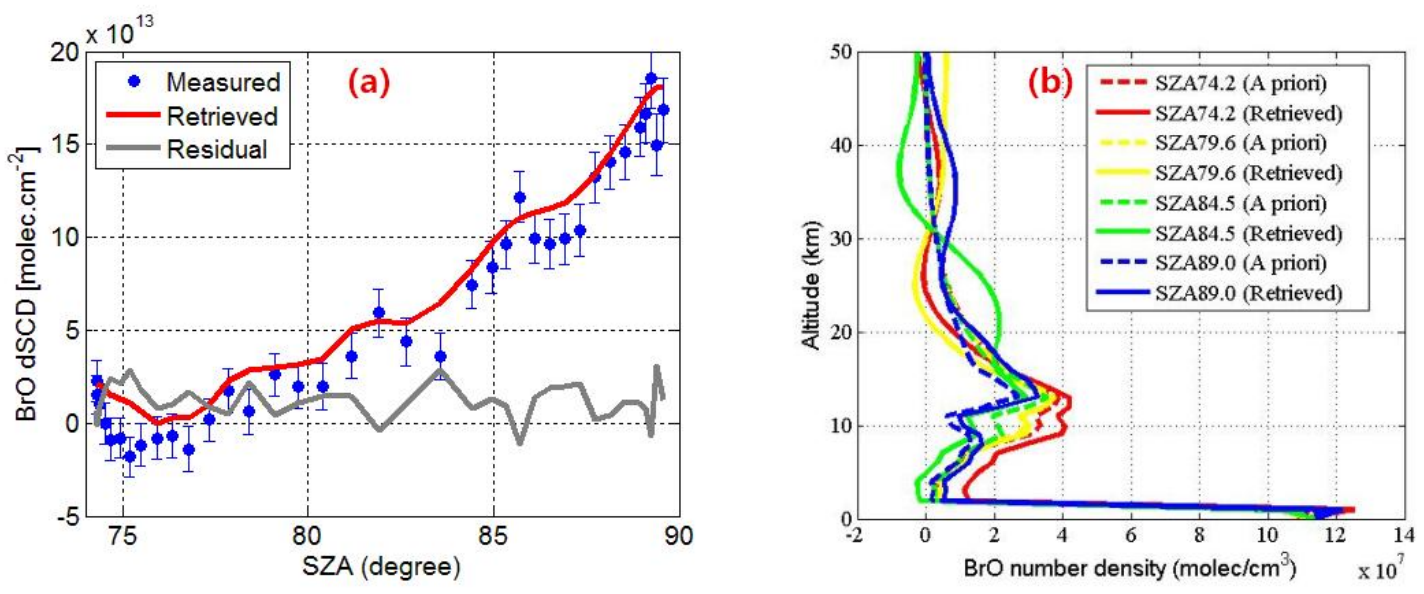

Fig. 3. (a) ZSL-DOAS measured and fitted $\mathrm{BrO}$ dSCDs and corresponding residuals at Eureka on 4 April 2011 PM; (b) BrO profiles retrieved from ZSL-DOAS data at various SZAs on 4 April 2011 PM. Solid lines indicate retrieved profiles, and dashed lines indicate a priori profiles (generated from the UM-UKCA chemistry-climate model). Note: These dSCDs are relative to local solar noon on 4 April.

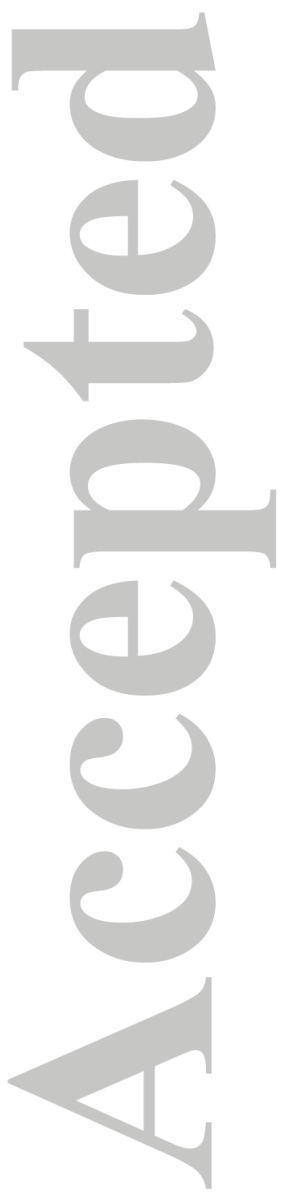




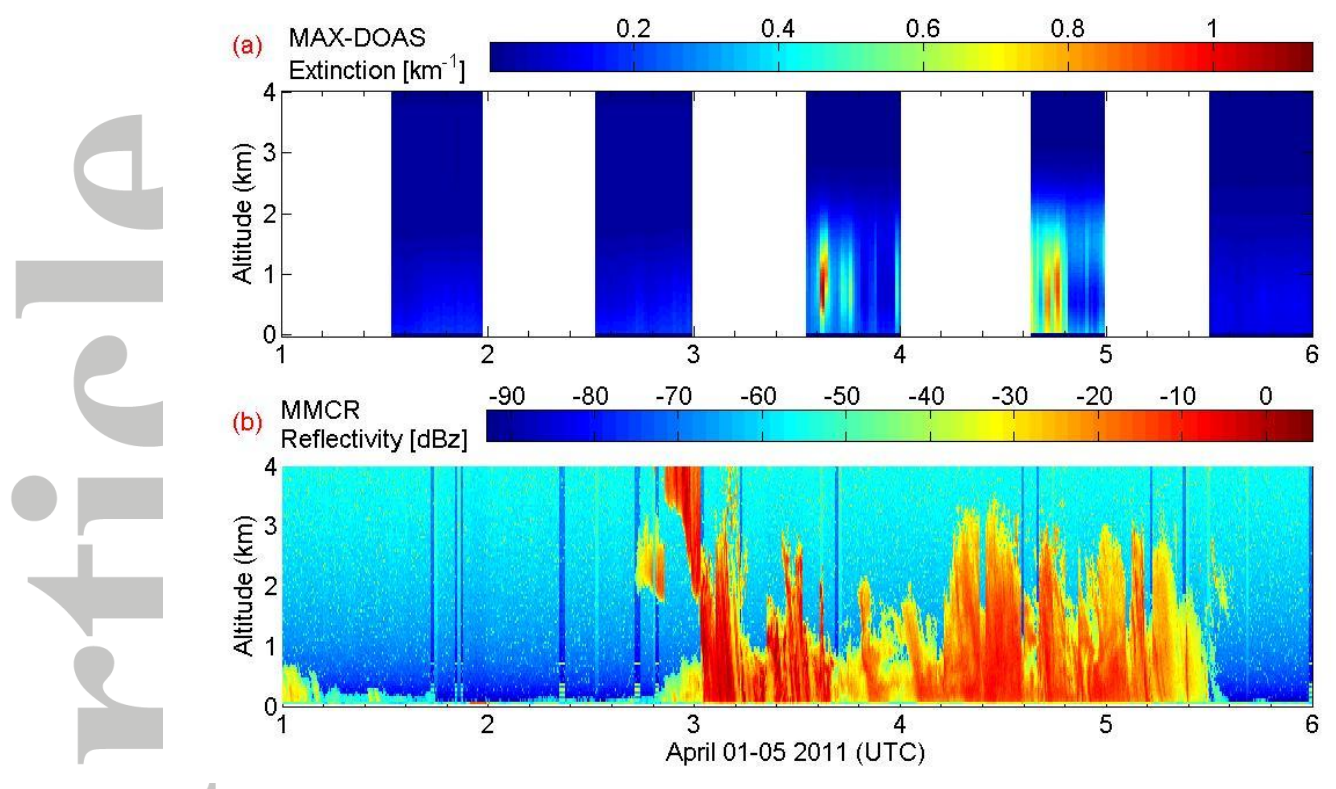

Fig. 4. (a) MAX-DOAS aerosol extinction profiles and (b) MMCR reflectivity from 1-5 April 2011. Note that the MAX-DOAS only works during sunlit conditions $\left(\mathrm{SZA}<86^{\circ}\right)$, while the MMCR works continuously.

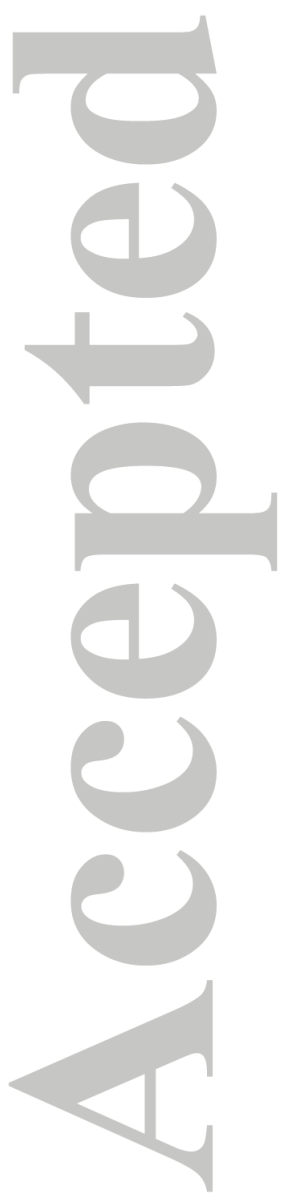



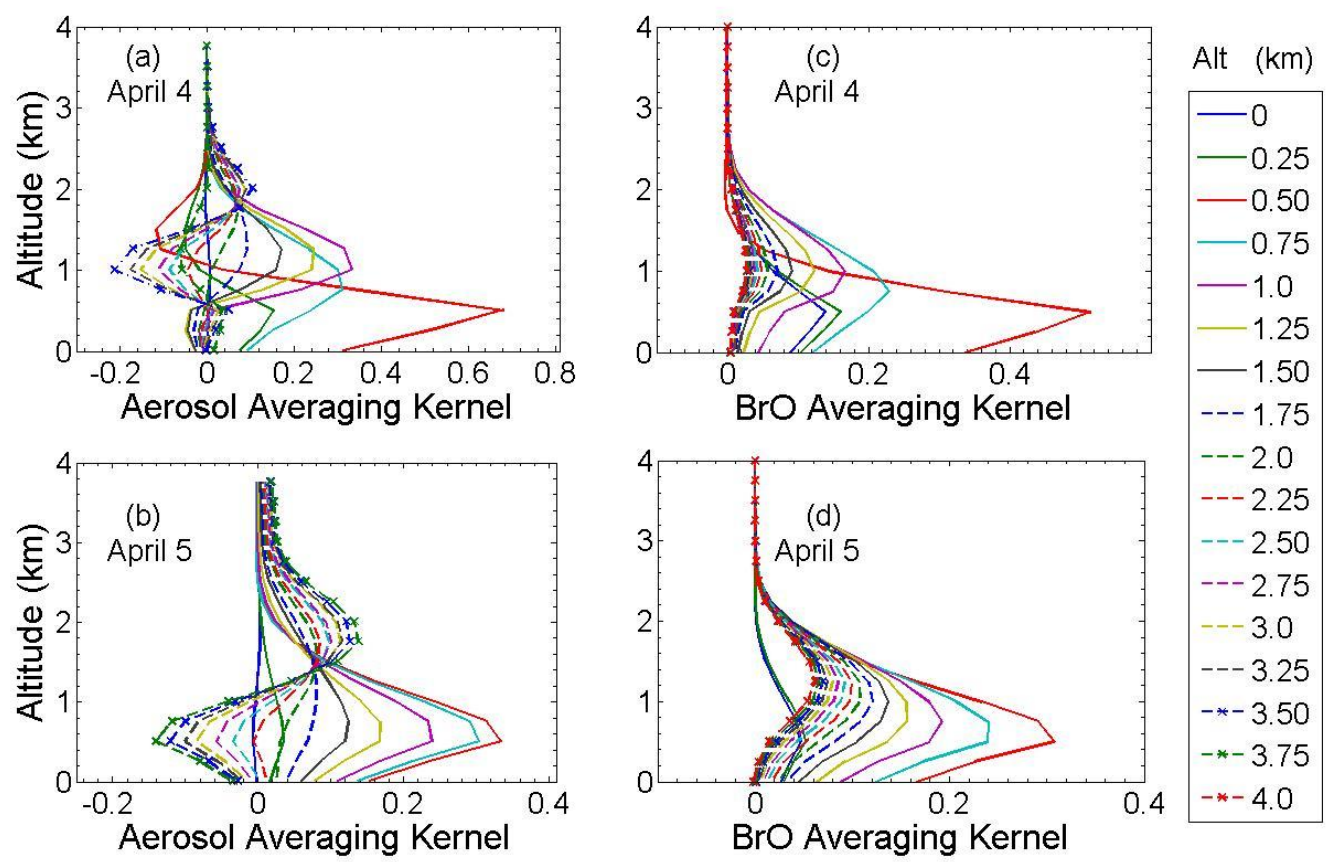

Fig. 5. MAX-DOAS 0-4 km averaging kernels for 4 and 5 April 2011 PM. (a) and (b) for aerosol extinction retrievals; (c) and (d) for $\mathrm{BrO}$ retrievals. 

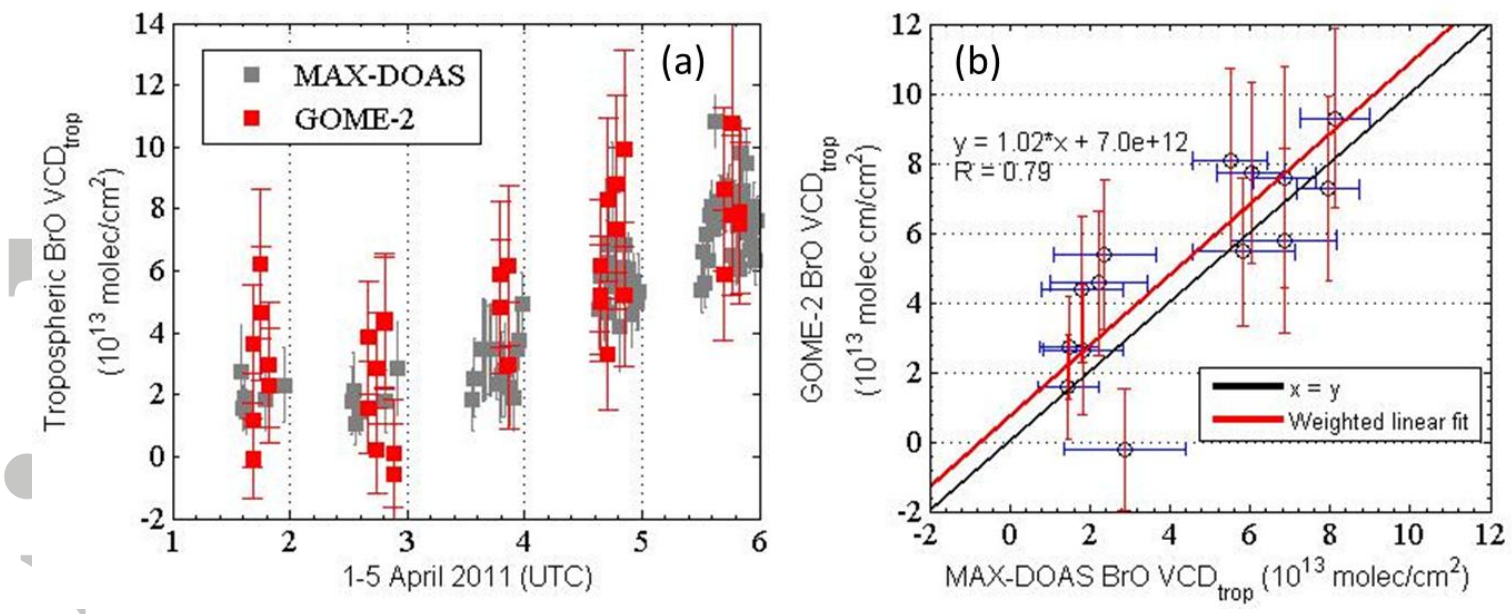

Fig. 6. (a) Time series of $\mathrm{BrO}$ tropospheric partial column densities $\left(\mathrm{VCD}_{\text {trop }}\right)$ from PEARLGBS MAX-DOAS (0-4 km altitude) and GOME-2 (approximately 0-8 km altitude, full troposphere) within $45 \mathrm{~km}$ of Eureka. (b) GOME-2 versus MAX-DOAS tropospheric BrO partial column densities. MAX-DOAS error bars are total retrieval error, based on Frieß et al. [2011]. GOME-2 error bars are systematic error, estimated based on Theys et al. [2011].

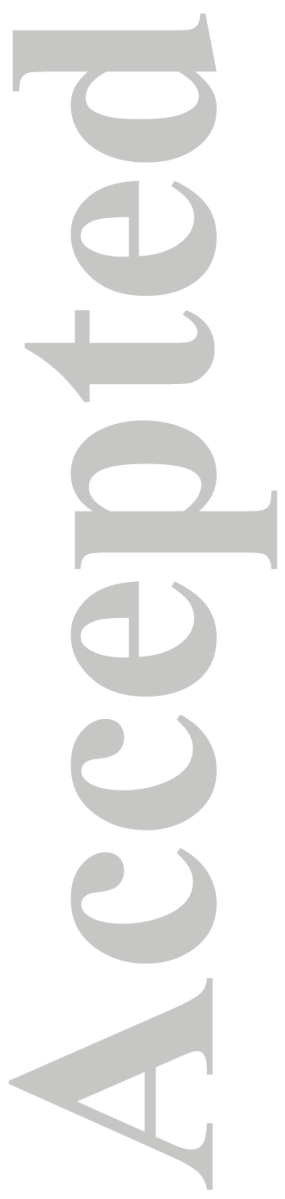


NOAA HYSPLIT MODEL

Backward trajectories ending at 0000 UTC 04 Apr 11

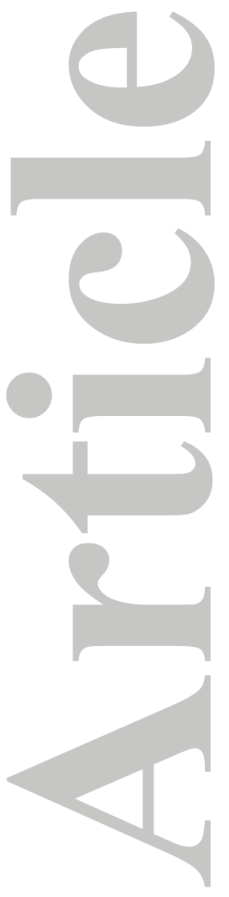

GDAS Meteorological Data

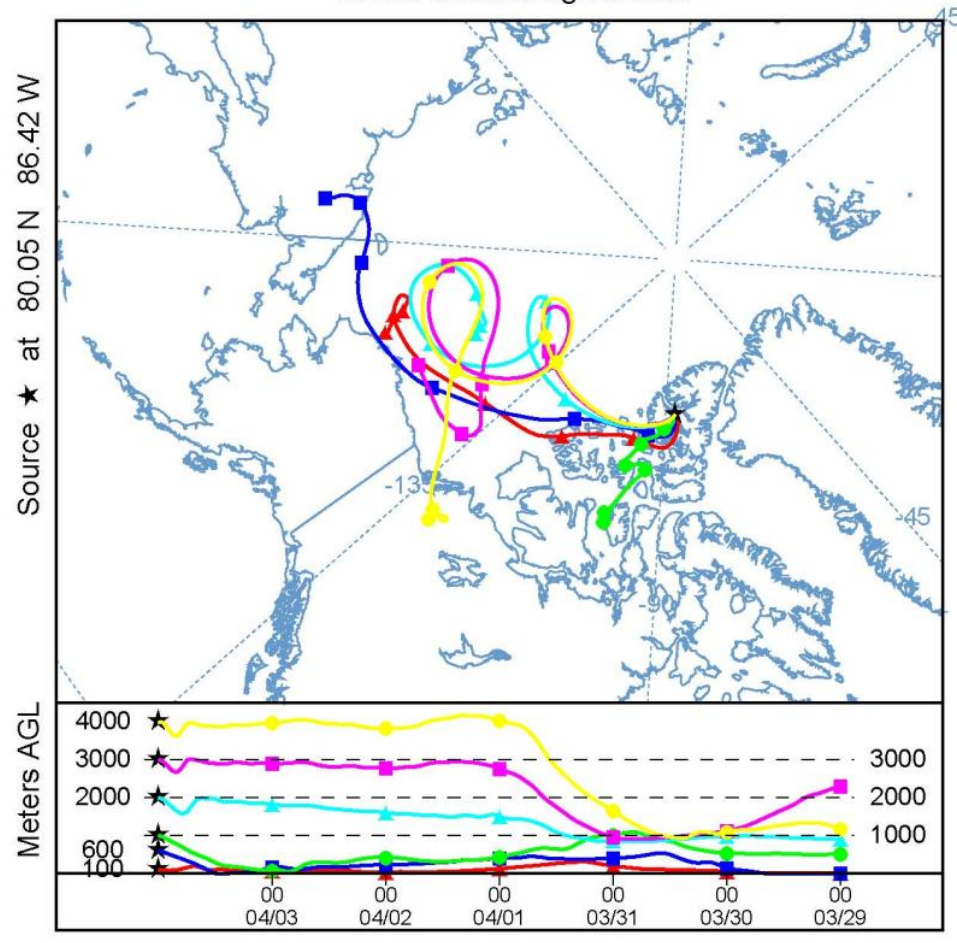

Fig. 7. HYSPLIT six-day back-trajectories for Eureka $\left(80.05^{\circ} \mathrm{N}, 86.42^{\circ} \mathrm{W}\right)$, ending at $00: 00$ UTC on 4 April 2011.

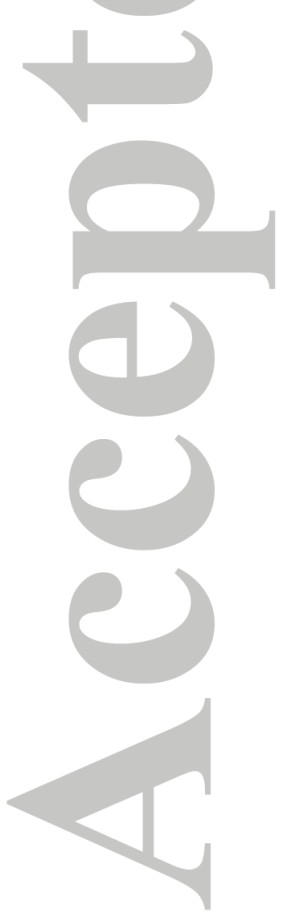




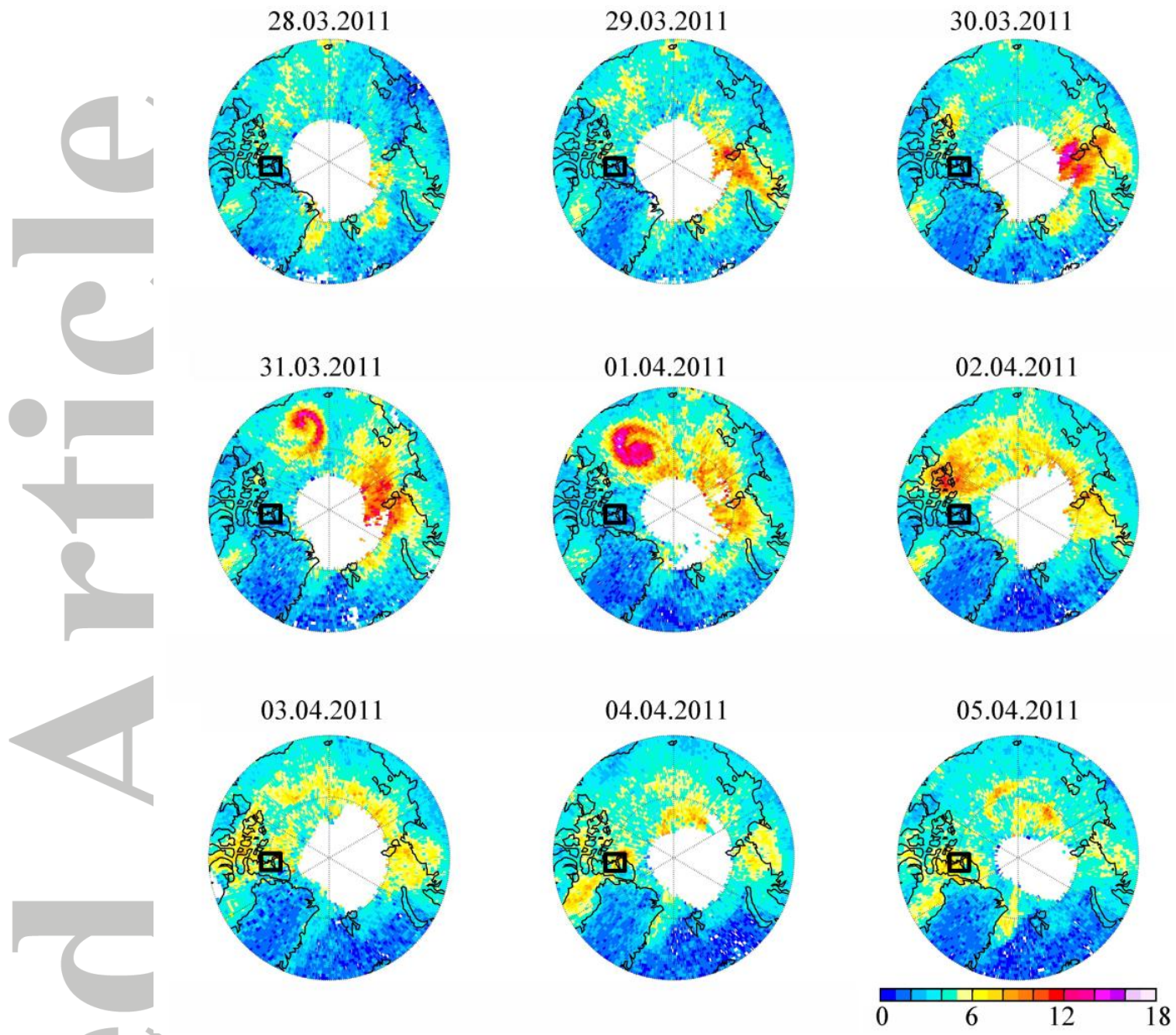

Fig. 8. GOME-2 BrO $\mathrm{VCD}_{\text {trop }}\left(\times 10^{13}\right.$ molec $\left.\mathrm{cm}^{-2}\right)$ north of $70^{\circ} \mathrm{N}$ from 28 March to 5 April 2011. The location of Eureka is indicated by the black square on each panel. 

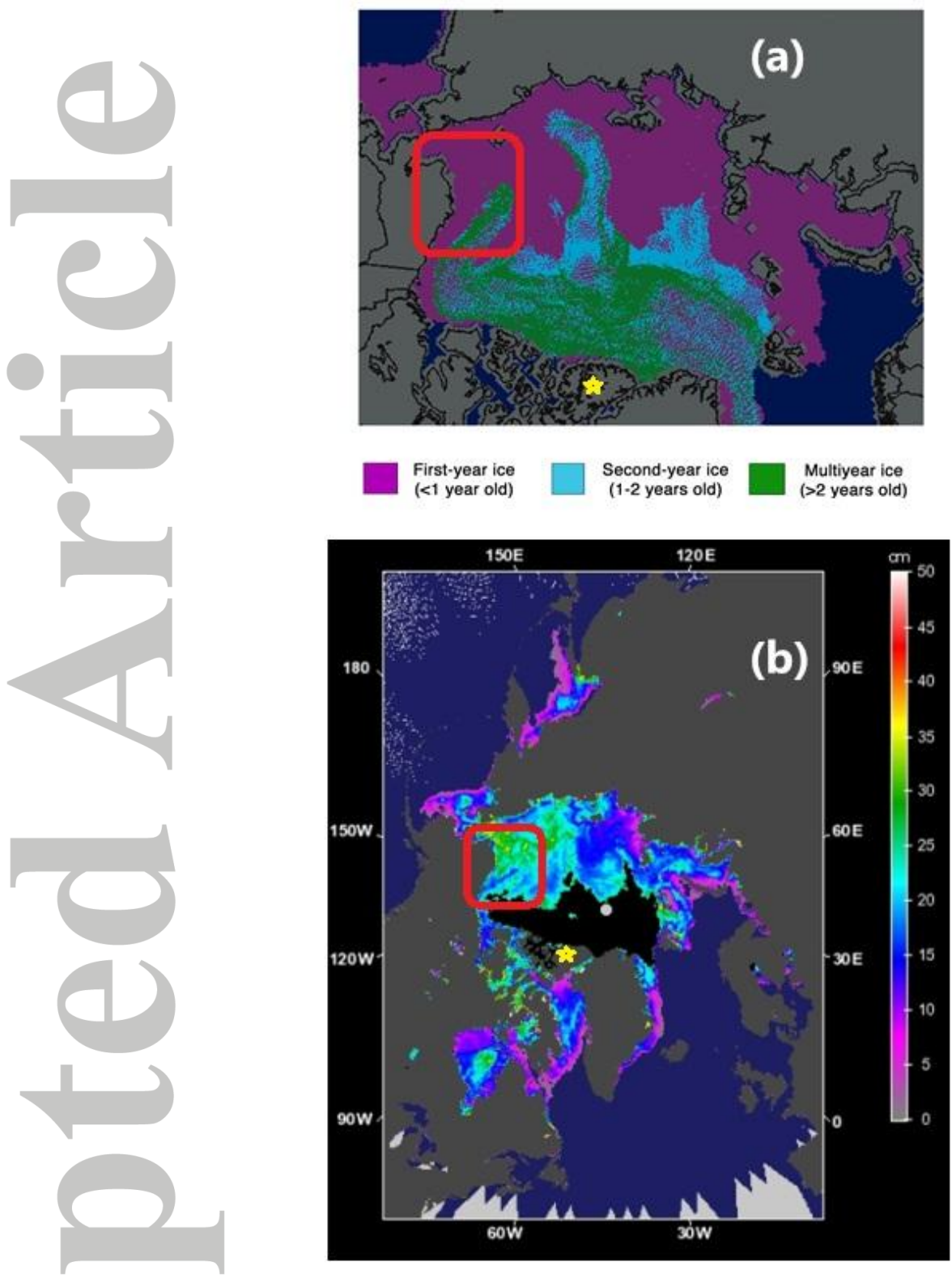

Fig. 9. Sea-ice and snow information. Eureka is indicated by the yellow star in both figures and the Beaufort Sea is indicated by the red box. (a) Arctic sea-ice age during the third week of March 2011. Figure adapted from NSIDC (Image courtesy of J. Maslanik and C. Fowler, and the NSIDC, University of Colorado, Boulder). (b) AMSR-E on Aqua snow depth over ice data, averaged from 31 March to 4 April 2011. Note that the Beaufort Sea was covered by $\sim 30 \mathrm{~cm}$ snow during this period. Figure adapted from NASA Distributed Active Archive Center at NSIDC (http://nsidc.org/data/amsre/data_summaries/index.html). 


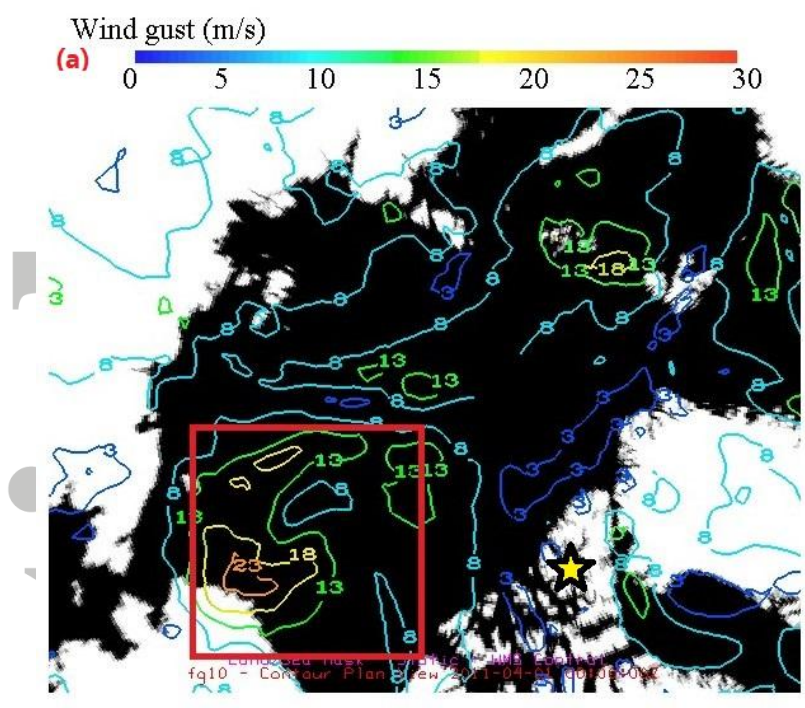

Boundary layer height (m)
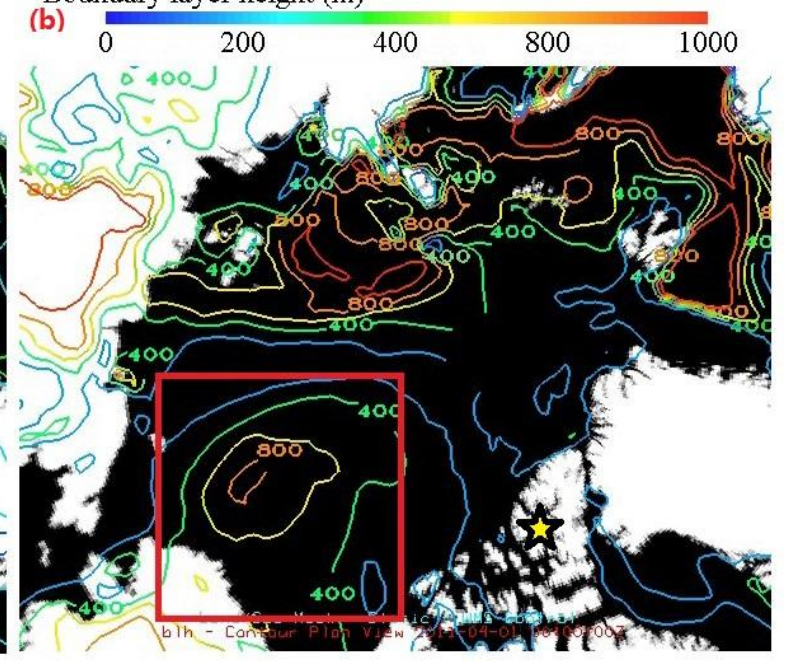

Fig. 10. ERA-interim data over the Beaufort Sea (indicated by the red box) for 00:00 UTC on 1 April 2011. (a) wind gust; (b) Boundary layer height. Eureka is indicated by the yellow star in both figures.

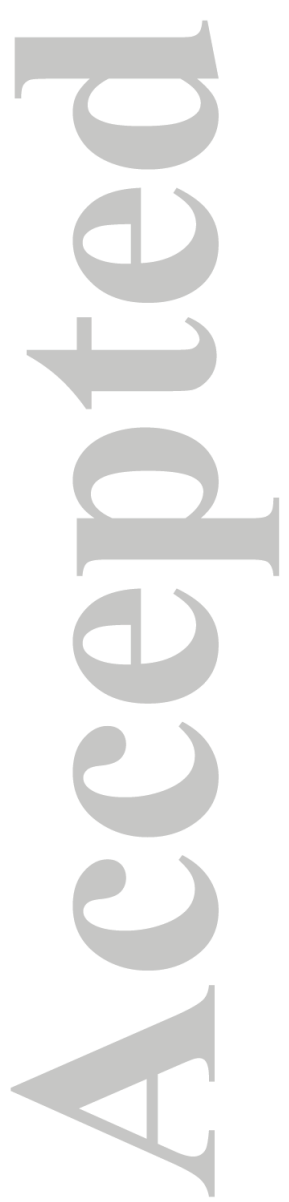




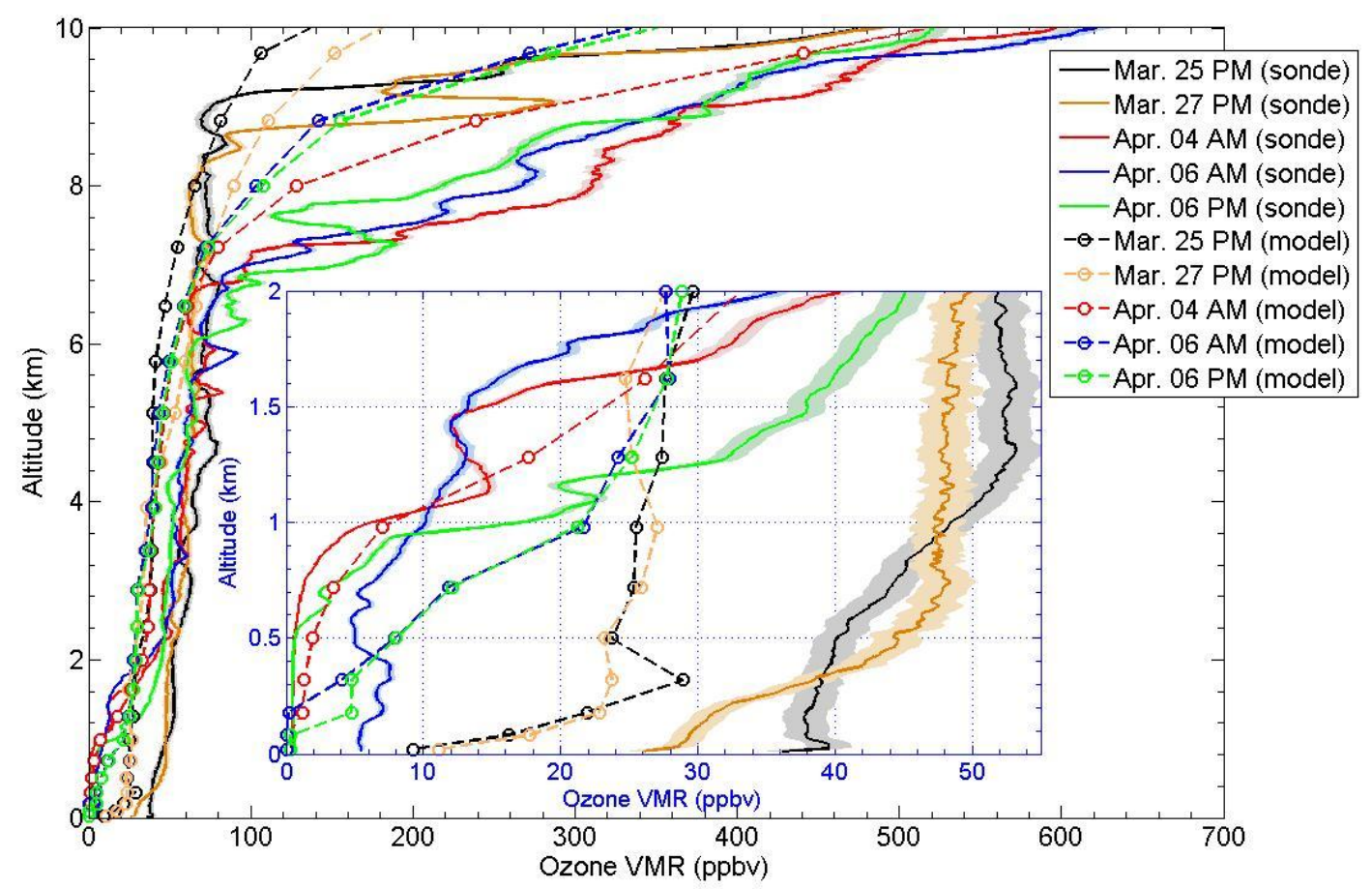

Fig. 11. Tropospheric ozone profiles above Eureka (the inset panel shows 0-2 km). Solid lines (as indicated in the legend) show ozonesonde measurements on 25 March (23:15 UTC), 27 March (23:15 UTC), 4 April (6:52 UTC), and 6 April (3:42 and 20:00 UTC) 2011, the shaded regions represent the 1-sigma uncertainty envelope. The dashed lines with circles show the UM-UKCA modeled ozone profiles for 25 March (23:00 UTC), 27 March (23:00 UTC), 4 April (7:00 UTC), and 6 April (4:00 and 20:00 UTC) 2011. 
(a)

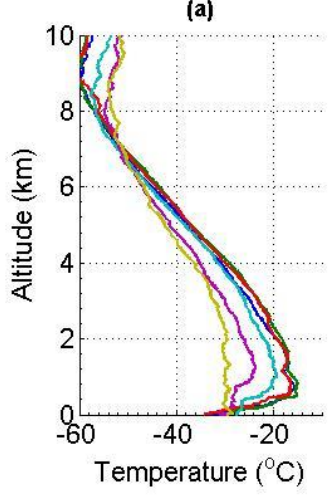

(b)

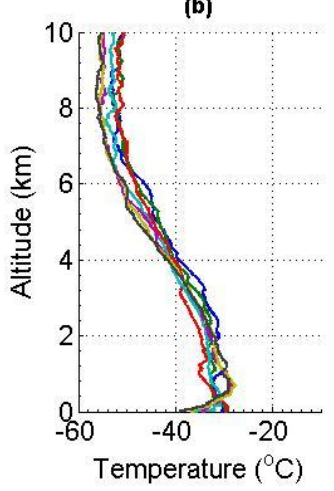

(c)

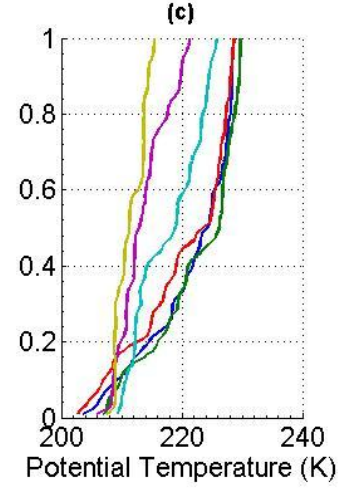

(d)

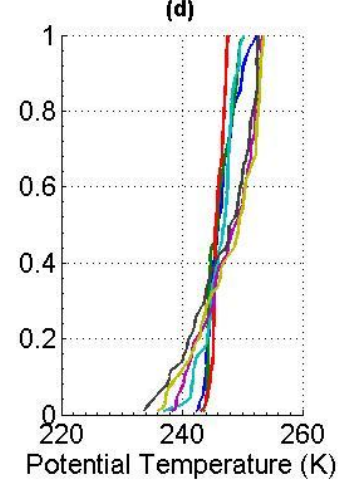

(e)

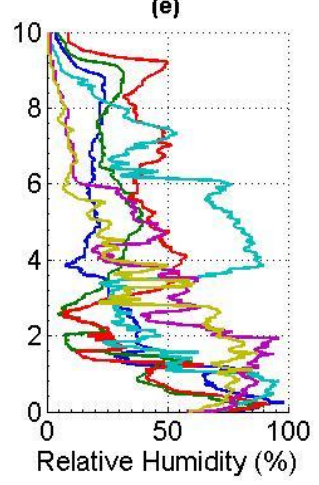

(f)

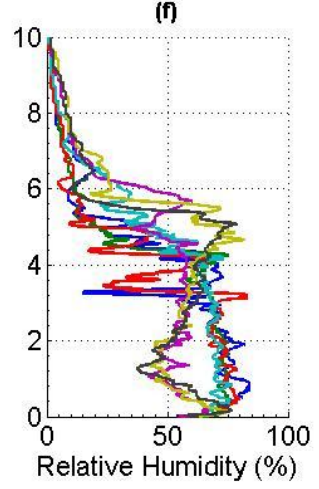

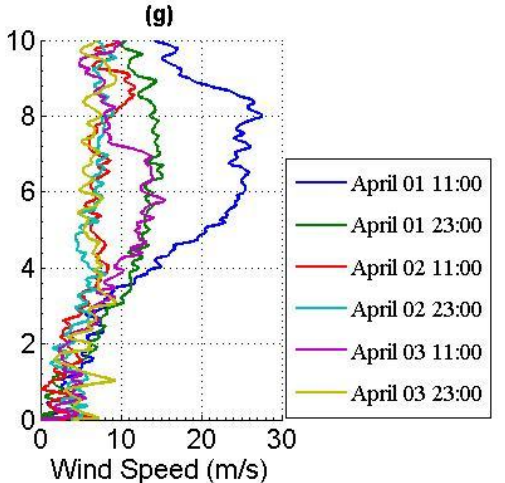

(h)

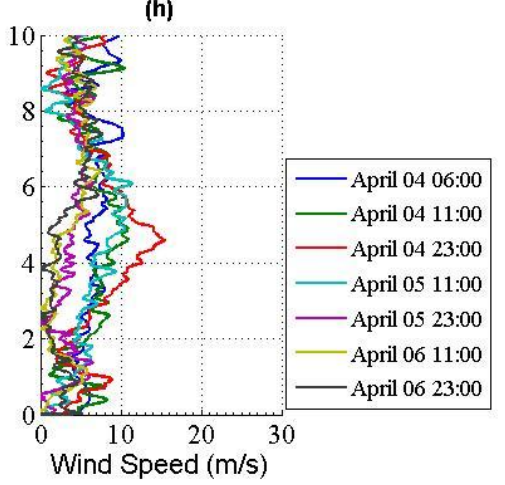

Fig. 12. Eureka radiosonde data from 1 to 6 April 2011, with launch times (UTC) indicated in the legends. Upper panels: 1-3 April, lower panels: 4-6 April. (a) and (b) temperature; (c) and (d) potential temperature; (e) and (f) relative humidity; (g) and (h) wind speed. Note: Panel (c) and (d) shows altitude range from 0-1 km. 


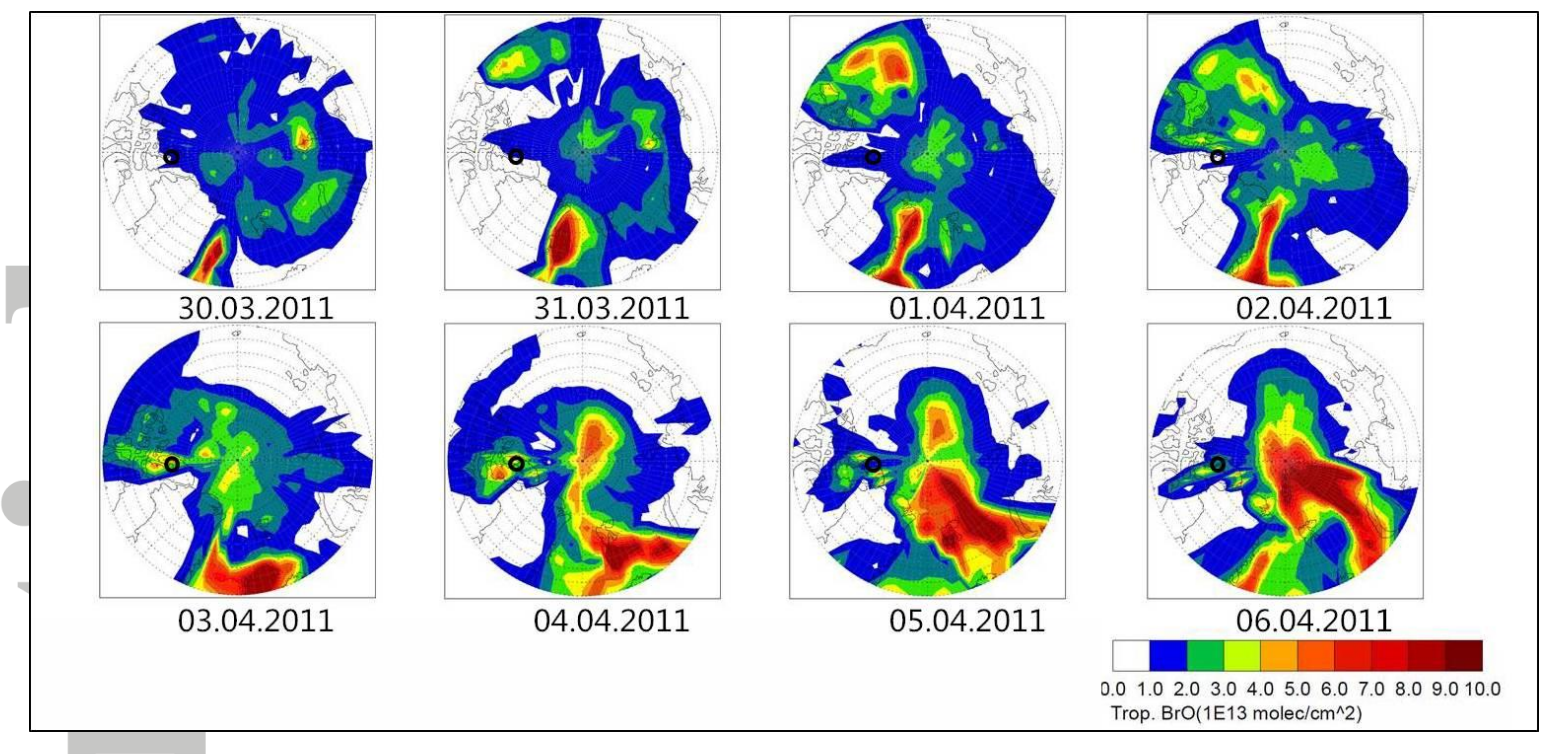

Fig. 13. UM-UKCA modeled tropospheric $\mathrm{BrO}$ (daily maximum value) for north of $60^{\circ} \mathrm{N}$ from 30 March to 6 April 2011. The location of Eureka is indicated by the black circle on the panels.

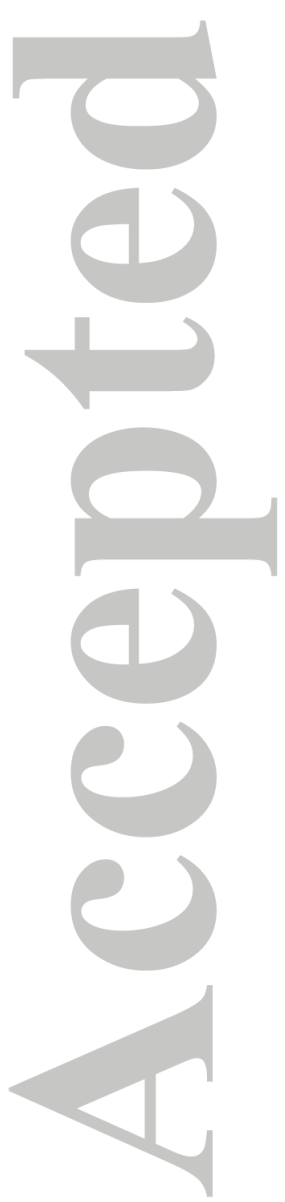



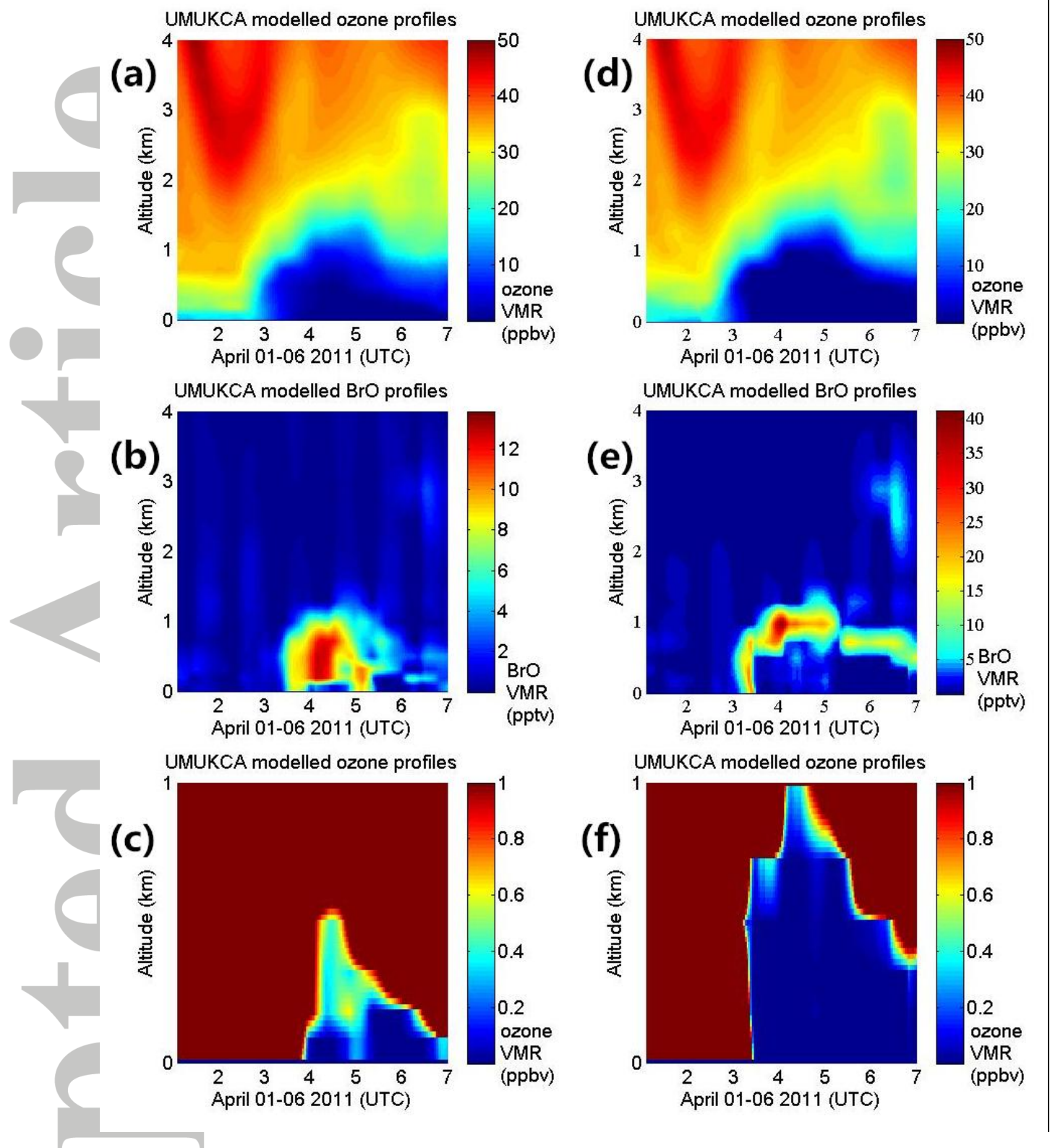

Fig. 14. UM-UKCA modeled $\mathrm{O}_{3}$ and BrO profiles for 1 to 6 April 2011 (UTC) over Eureka. The left column (panels a, b, and c) shows runs with a low bromine release flux, the right column (panels d, e, and f) shows runs with a high bromine release flux. (a) and (d) 0-4 km ozone profiles; (b) and (e) 0-4 km BrO profiles; (c) and (f) 0-1 km ozone profiles with $1 \mathrm{ppbv}$ mask. Note: To show the detailed structure of the modeled bromine plume and ozone vertical structures, the colour scale for panel (e) is different from panel (b), and the altitude range for panels (c) and (f) is $0-1 \mathrm{~km}$. 

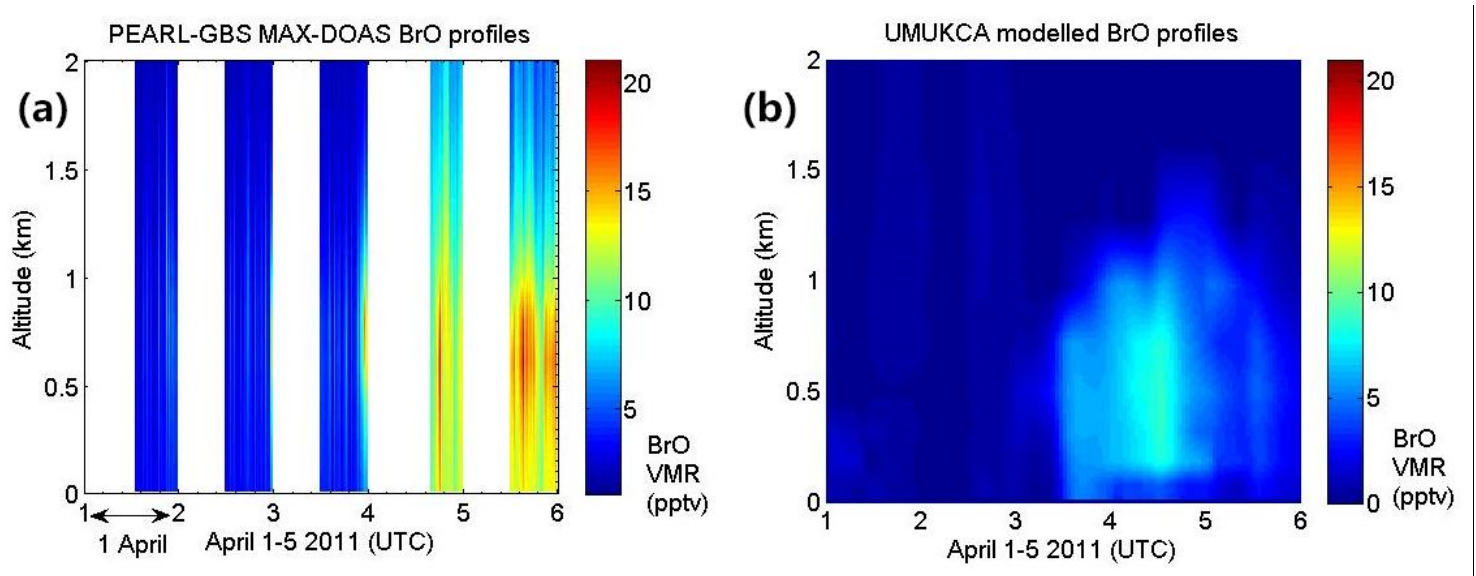

Fig. 15. (a) MAX-DOAS tropospheric $\mathrm{BrO}$ profiles measured at Eureka; (b) UM-UKCA modeled tropospheric $\mathrm{BrO}$ profiles over Eureka on the same colour scale as (a). Note: the modeled $\mathrm{BrO}$ in Fig. 15b is the same as in Fig. 14b. Fig. 15 highlights the lowest $2 \mathrm{~km}$, and uses a different colour scale for comparison with the MAX-DOAS measurements.

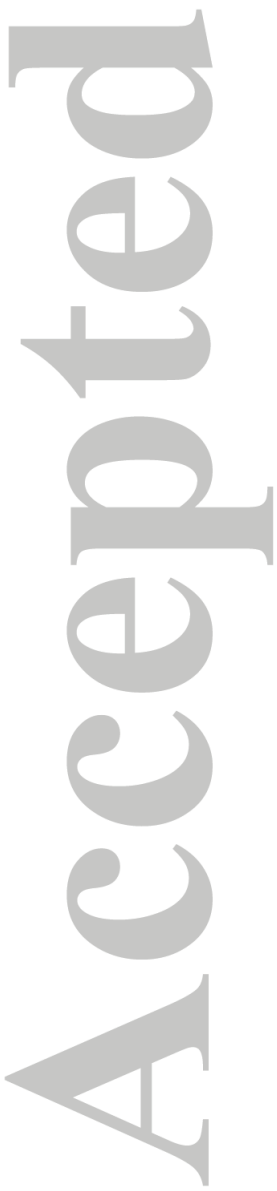



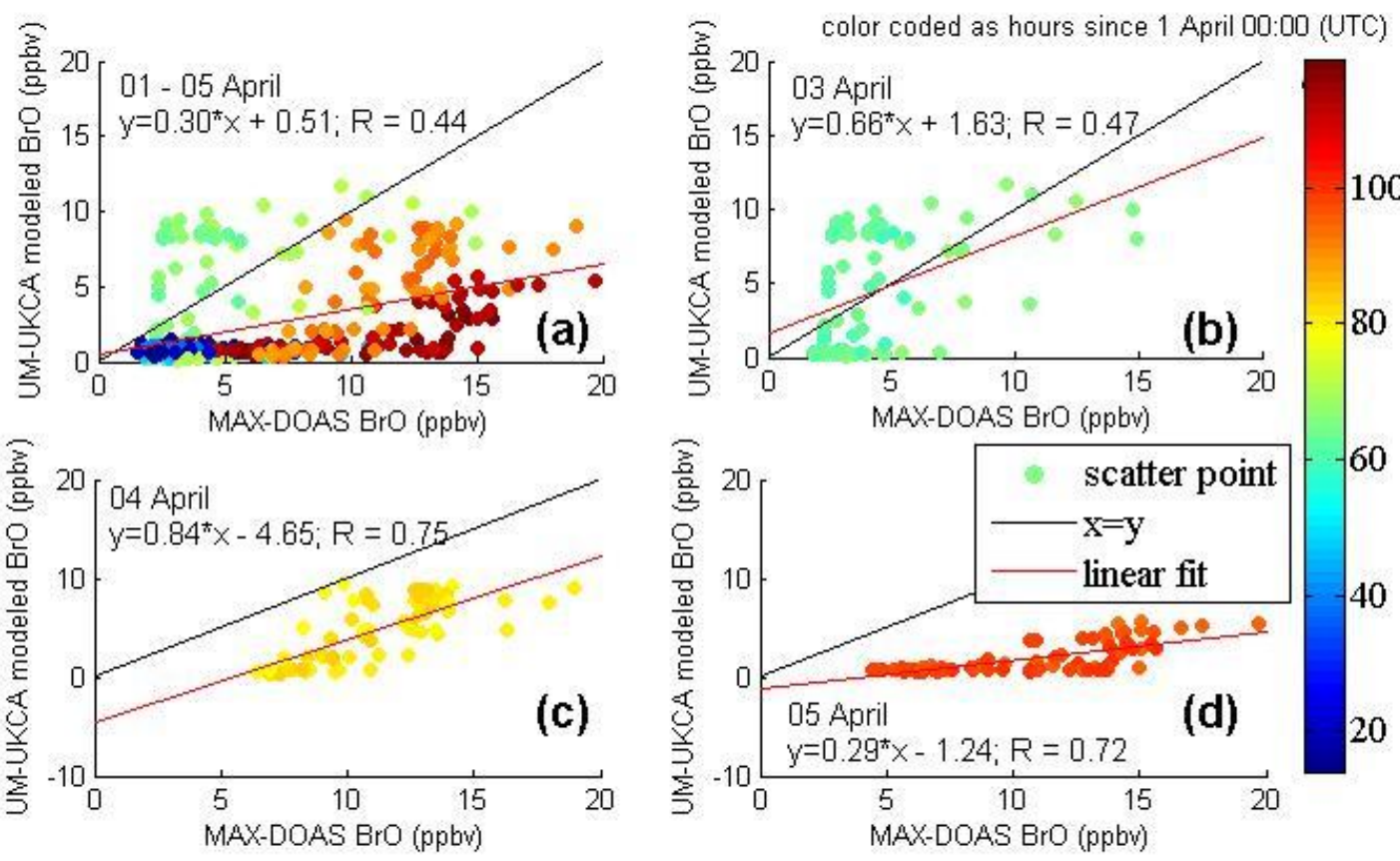

Fig. 16. UM-UKCA modeled BrO partial columns $(0-4 \mathrm{~km})$ versus MAX-DOAS measurements at Eureka. All scatter points are colour coded by time, in hours since 1 April 00:00. Data are shown for: (a) 1 to 5 April (the complete data set), (b) 3 April, (c) 4 April, and (d) 5 April. 


\section{University Library}

\section{- M M N E R VA A gateway to Melbourne's research publications}

Minerva Access is the Institutional Repository of The University of Melbourne

\section{Author/s:}

Zhao, X;Strong, K;Adams, C;Schofield, R;Yang, X;Richter, A;Friess, U;Blechschmidt, $\mathrm{AM} ; \mathrm{KoO}, \mathrm{JH}$

Title:

A case study of a transported bromine explosion event in the Canadian High Arctic

Date:

2016-01-16

\section{Citation:}

Zhao, X., Strong, K., Adams, C., Schofield, R., Yang, X., Richter, A., Friess, U., Blechschmidt, A. M. \& Koo, J. H. (2016). A case study of a transported bromine explosion event in the Canadian High Arctic. Journal of Geophysical Research, 121 (1), pp.457-477. https://doi.org/10.1002/2015JD023711.

Persistent Link:

http://hdl.handle.net/11343/58900 